\title{
Fluidic Fuel Feed System
}

\section{Final Report}

P. Badgley

June 1990

Work Performed Under Contract No.: DE-AC21-86MC23006

For

U.S. Department of Energy

Office of Fossil Energy

Morgantown Energy Technology Center

Morgantown, West Virginia

By

Adiabatics, Inc.

Columbus, Indiana 


\section{DISCLAIMER}

This report was prepared as an account of work sponsored by an apency of the United States Government. Neither the United States Government nor any agency thereof, nor any of their employes, mukes eny warranty, express or implied, or assumes any lepal lisbility or responsibility for the accuracy, completeness, or usefuliness of any information, apparatus, product, or process disclosed, or represents that its use would not infringe privately owned rights. Reference herein to any specific commercial product, process, or service by irade name, trademark. manufacturet, or otherwise does not necescarily constitute or imply its endorsement, recommendation, or favoring by the United Srates Government or any agency thereof. The views and opinions of authors ex. pressed herein do not necescarily stace or reilect those of the United Sumes Government of any arency thereor.

This repon has been reproduced directly from the best available copy.

Available to DOE and DOE contractors from the Office of Scientific and Technical Information, P.O. Box 62, Oak Ridge, TN 37831; prices available from (615)576-8401, FTS 626.8401.

Available to the public from the National Technical Information Service, U.S. Department of Commerce, 5285 Port Royal Rd., Springfield, VA 22161. 
Fluidic Fuel Feed System

Final Report

P. Badgley

Work Performed Under Contract No.: DE-AC21-86MC23006

\author{
For \\ U.S. Department of Energy \\ Office of Fossil Energy \\ Morgantown Energy Technology Center \\ P.O. Box 880 \\ Morgantown, West Virginia 26507-0880
}

By

Adiabatics, Inc. 3385 Commerce Drive

Columbus, Indiana 47201

June 1990 
Adiabatics, Inc. would like to acknowledge the following organizations and individuals who have performed key functions in making this project a success:

First and foremost is the help and guidance which have been received from METC's Contracting Officer's Technical Representative (COTR) Mr. William C. Smith and the previous COTR Mr. Michael McMillian, and others at METC. including $\mathrm{Mr}$. Mark Hobrlay who was instrumental in encouraging and sponsoring the project.

Next are the two suhcontractors; Defense Research Technologies, Inc. and Teknocraft, Inc. The technical direction and design of the fluidic components was led by $\mathrm{Mr}$. Alan Holmes of DRT with the fabrication and bench testing efforts at Teknocraft conducted by Mr. Sam Kumar and his staff.

The author would like to thank Adiabatics, Inc. personnel: Mr. Douglas Doup and Mr. David McNulty for their engineering help, Mr. Michael Greathouse for design and drafting and $\mathrm{Mr}$. Michael Baker for his help in bench testing the hardware and in conducting the engine test program. 
FLUIDIC COAL FEED SYSTEM

Table of Contents

Page No.

DISCLAIMER . . . . . . . . . . . . . . . . . . . . . . . . . . . . . . . . . .

TITLE PAGE . . . . . . . . . . . . . . . . . . . . . . . . . . . . . . . . .

ACKNOWLEDGMENTS . . . . . . . . . . . . . . . . . . . . . . . . . . . . . . . . . .

LIST OF FIGURES. . . . . . . . . . . . . . . . . . . . . . . . . . e v

EXECUTIVE SUMMARY. . . . . . . . . . . . . . . . . . . . . . 1

1.0 INTRODUCTION. . . . . . . . . . . . . . . . . . . . . . 1

1.1 BACKGROUND. . . . . . . . . . . . . . . . . 2

1.2 PROGRAM OBJECTIVES . . . . . . . . . . . . . . . . 2

2.0 PROJECT DESCRIPTION . . . . . . . . . . . . . . . . . . . . . . . . . . . . 3

2.0.1 RESULTS AND ACCOMPLISHMENTS. . . . . . . . . . . 8

2.1 TECHNICAL APPROACH . . . . . . . . . . . . . . 8

2.1 .1 VORTEX SWIRL NOZZLE . . . . . . . . . . . 9

$\begin{array}{lll}2.1 .1 .1 \text { THEORY OF SWIRL NOZZLE OPERATION } & 10 \\ & 12\end{array}$

2.1 .2 VORTEX THROTTLING VALVE . . . . . . . . . $\quad 12$

$\begin{array}{llll}2.1 .2 .1 & \text { THEORETICAL OPERATION OF VORTEX } & 14 \\ \text { VALVES . . . . . . . . . . . . . . } & . & 14\end{array}$

2.1.3 VORTEX THROTTLINS, NOZZLE. . . . . . . . . 15

2.1 .4 SLURRY FUEL CONTROL CIRCUITS. . . . . . . 15

2.2 TEST FACILITY DESCRIPTION. . . . . . . . . . . . 17

2.2.1 COAL SLLRRY SYSTEM. . . . . . . . . . . 17

2.2.2 AIR SUPPLY SYSTEM . . . . . . . . . . . . 18

2.2.3 INJECTOR DRIVE ELECTRONICS. . . . . . . . 19

2.2.4 TEST ENGINE . . . . . . . . . . . . . . . 19

2.2 .5 INSTRUMENTATION . . . . . . . . . . . 20

2.3 FLUIDIC INJECTOR HARDWARE. . . . . . . . . . . 20

3.0 BENCH TEST RESULTS. . . . . . . . . . . . . . . . . . . . . 23

4.0 ENGINE TESTING. . . . . . . . . . . . . . . . . . . . . . . 29

5.0 ENGINE DATA ANALYSIS. . . . . . . . . . . . . . . . . . . 32

6.0 SUMMARY AND CONULUSIONS . . . . . . . . . . . . . . . . . . . . $\quad 34$

7.0 RECOMMENDATIONS FOR FUTURE WOFK . . . . . . . . . . . . . 35

8.0 REFERENCES. . . . . . . . . . . . . . . . . . . . . . . . $\quad 37$

9.0 LIST OF ACRONYMS, ABBREVIATIONS, AND SYMBOLS. . . . . . $\quad 38$ 


\section{List of Figures}

\section{Eigure}

1

2

3

4

5

6
Title

Page

Fluidic Fuel Feed System. . . . . . . 3

Swirl Nozzle. . . . . . . . . . 9

Sample Calculations of Mean Drop

Diameters . . . . . . . . . . . 11

Fluidic Vortex Throttling Valve . . . 12

Vortex Valve Operating Characteristics , 13

Vortex Throttling Nozzle. . . . . . . 16

Circuit Illustrating a Solenoid-Actuated Vortex Throttling Nozzle in a Common Rail Type Fuel Distribution System . . . . 17

CWS Handling System . . . . . . . . 18

Air Supply System ... . . . . . . . 19

Injector Electronics. . . . . . . . . 21

Test Engines Modifications. . . . . . 21

VTN Injector Operation. . . . . . . . 21

Back-up Injector 非 . . . . . . . . . 22

Back-up Injector 非 . . . . . . . . . 23

Primary Injector Design \#3. . . . . . 24

Back-up 非 Performance. . . . . . . . 25

VTN Geometries. . . . . . . . . . 26

Vortex Valve. . . . . . . . . . 26

Back-up Injector \#2 Performance... . 28

CWS Feed Check Valve. . . . . . . . . 28

Control Air \& CWS Check Valves in \#3 Injector.............. 30

Diesel Combustion.......... . 33 
FLUIDIC COAL FEED SYSTEM

\section{List of Figures}

Eigure

Title

Page

23

Coal Water Slurry/Diesel. . . . . . .

33

24

Air Compressor Power Requirement Percent

of Engine Power . . . . . . . . . . . .

Hybrid Injector . . . . . . . . . .

36

\section{Tables}

Fluidic Fuel Feed System - Research

Team Participation. . . . . . . . .

Fuel Feed Specifications. . . . . .

Engine Test Data. . . . . . . . . 
This report documents the development and testing of a fluidic fuel injector for a coal-water slurry fueled diesel engine. The objective of this program was to improve the operating life of coal-water slurry fuel controls and injector components by using fluidic technology. This project addressed the application of fluidic devices to solve the problems of efficient atomization of coal-water slurry fuel and of injector component wear. The investigation of injector nozzle orifice design emphasized reducing the pressure required for efficient atomization. The effort to minimize injector wear includes the novel design of components allowing the isolation of the coal-water slurry from close-fitting injector components. The program has successfully shown by a "Proof of Concept" test that a fluidic injector can be used for this application. The fluidic system in this program operated for thirty minutes on a single cylinder diesel engine. The durability of the injector was not investigated because of time and budgetary constraints. This task of the program has proven to be much more difficult than originally predicted and required extensive innovation to solve some very difficult (unforeseen and difficult to diagnose) problems.

Three totally different injectors were designed, fabricated, bench tested and modified to arrive at a final design which was capable of being engine tested. The final injector ended up requiring the addition of two check valves in the slurxy feed passage and one in. the air line to make the injector function. adequately. Unfortunately, these modifications make the injector potentially less reliable and violates the fluidic requirement of "no moving parts in the CWS stream."

This report uses the results of this progras to make recommendations for future work which can build on the current knowledge and experience base to apply fluidics towards making a practical production CWS fuel injection system.

\subsection{INTRODUCTION}

This final report documents the program activities as part of DOE Contract No. DE-AC 86MC23006 which concluded January 22, 1990. 


\subsection{BACKGROUND}

The success of coal fired internal combustion engines is dependent upon successfully solving some key technical problems including the clogging and excessive wear of the fuel injection hardware. This project was designed to determine the feasibility of a fluidic fuel injection system which eliminates the small orifices which clog, and the tight-clearance rubbing surfaces which suffer severe abrasive wear by providing a fuel injection system, based on fluidics technology, with no moving parts and a large flow path. A project with five tasks was generated and documented in a Management Plan (Reference 1) which was the first deliverable of the program and provided direction to the project and set intermediate and final goals.

\subsection{PROGRAM OBJECTIVES}

The objective of this program was to improve the operating life of coal slurry fuel controls and injector components by using fluidic technology. No-moving-parts fluidic fuel control and injection systems were to be analyzed, designed, bench tested and engine tested to confirm that the problems of wear and clogging can be significantly reduced or eilminated in a coal-water slurry fueled diesel engine. Specific technical objectives include:

- Identification of fluidic flow control and atomization techniques that were applicable to the design of coal slurry fuel injector functions.

- Design, fabrication and bench testing fluid control components which can be used to implement control or injection circuits.

- Design, fabrication and bench testing of a breadboard fuel injection system which combines the individual fluidic cumponents into a complete system.

- Design, fabrication and bench and engine testing of a fluidic fuel injector in a coal fueled diesel engine. 


\subsection{PROJECT DESCRIPTION}

This project addressed the application of fluidic devices to solve the problems of efficient atomization of coal slurry fuel and of injector component wear. The investigation of injector nozzle orifice design emphasized reducing the pressure required for efficient atomization. The effort to minimize injector wear includes the novel design of components allowing the isolation of the coal slurry from close-fitting injector components.

Figure 1 illustrates, the schedule for the major program activities. In order to bring together all of the disciplines necessary to accomplish this program a team was formed consisting of Adiabatics, Inc. (AI) as the prime contractor with responsibility for overall program coordination as well as engine testing. Defense Research Technologies (DRT) was responsible for the basic fluidic elements and systems designs as well as system and component analysis. The key participant at DRT was Mr. Allen Holmes who was an employee of Harry Diamond Laboratory who worked as a consultant at DRT. The third participant was Teknocraft, Inc. (TI). Mr. Sam Kumar, the president of TI, had an extensive background in fluid mechanics and fluidic element fabrication. The fourth participant was the Eaton Corporation who was to provide inputs on the manufacturability of the resultant fuel injection system. Table 1 is a listing of the participants and the program tasks and key subtasks with designations (open squares) showing participants in each subtask and (solid squares) designations for primary responsibility for each subtask.

\section{FLUIDIC FUEL FEED SYSTEM}

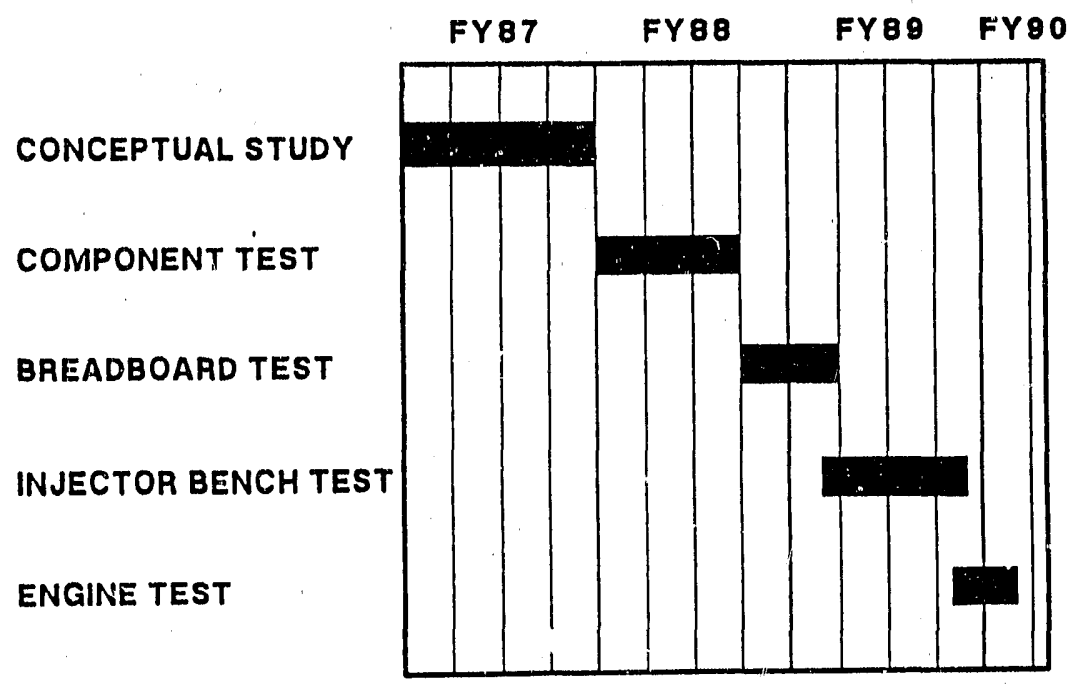

FIGURE 1. FLUIDIC FUEL FEED SYSTEM 


\section{FLUIDIC FUEL FEED SYSTEM \\ RESEARCH TEAM PARTICIPATION}

TASK A DESIGN AND TEST PLAN

Syetem' Requiremente

Analyese and Dovalopment of Concept Design of Fluidic System Concapt

Tast Plan Submittod to DDE

TASK 2, LABORATORY TESTING

Fabricotion of Lob Scale Syetam Laborotory Scale Tacts

Topjeol Roport for DOE-COTR

TASK 3 \& PROTOTYPE TEST PLAN

Prototypo Dosign for 3 Fuale

Test Plan for Prototype

Subendt Prototype Teet Plon

TASK 4: PROTOTYPE TESTING

Fabrication of Prototype System Engina Testing of Prototype Analyeir of Test Resulte

TASK 5 (OPTIONAL)

Modification of Prototypo Multi-cylinder Tasting 3-Fuale Comprehansive Raport Submitted Design Improvamente Report

ADIABATICS DRT. INC. TEKNOCRAFT EATON CORP.

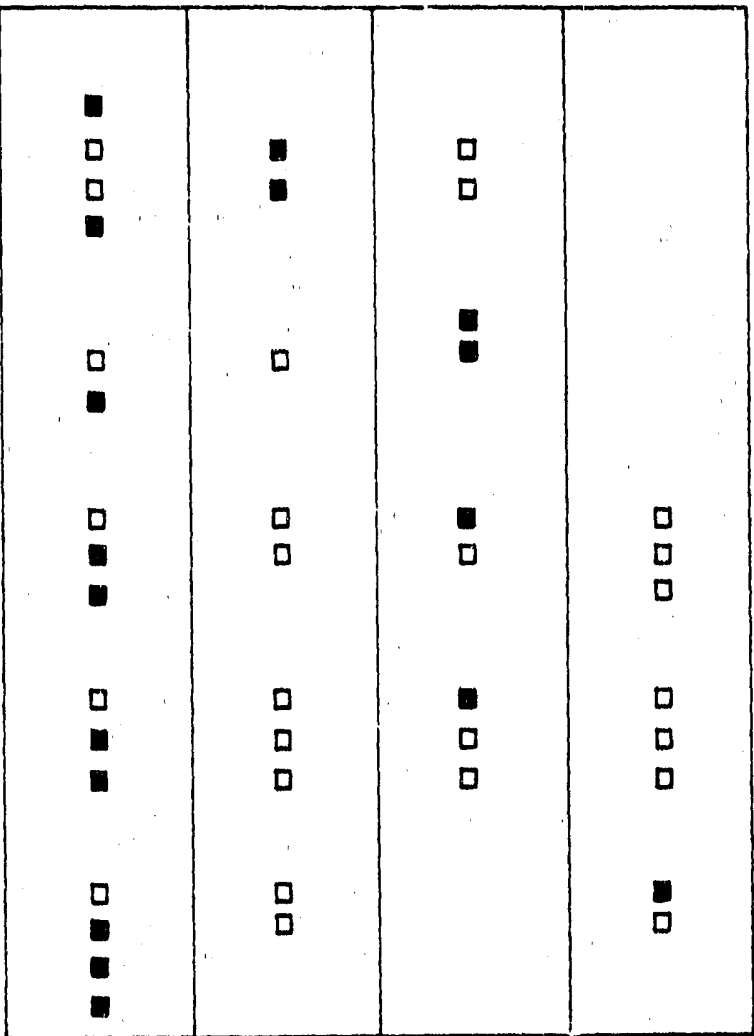

TABLE 1

The second and third required deliverable items were the Test Plan and the Topical Report for Task I (reference 2), which documented the findings of the conceptual design and provided a plan for testing system components to determine how the components react with coal-water slurry as the fluid medium. These items were delivered December 1987. The major results and accomplishments of Task I are summarized as follows:

Establishment of fuel flow specification for a fluidic slurry fuel handling and control system as shown in Table 2 . 


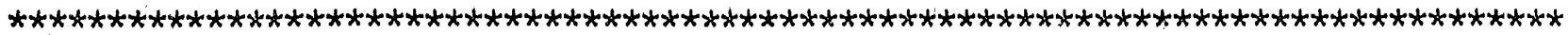

Table 2

FUEL FEED SPECIFICATIONS

\section{Pressures}

Injection Pressure $17.2 \mathrm{MPa}$ (2500 psi) minimum

Cylinder Pressure (during inj) $0.69-4.83 \mathrm{MPa}(100-700 \mathrm{psi})$

Peak Cylinder Pressure $7.58-10.3 \mathrm{MPa}$ (1100 - $1500 \mathrm{ps} 1)$

Minimum Cylinder Pressure $70 \mathrm{kPa}$ (10 psia)

\section{Fuel Flow Rates}

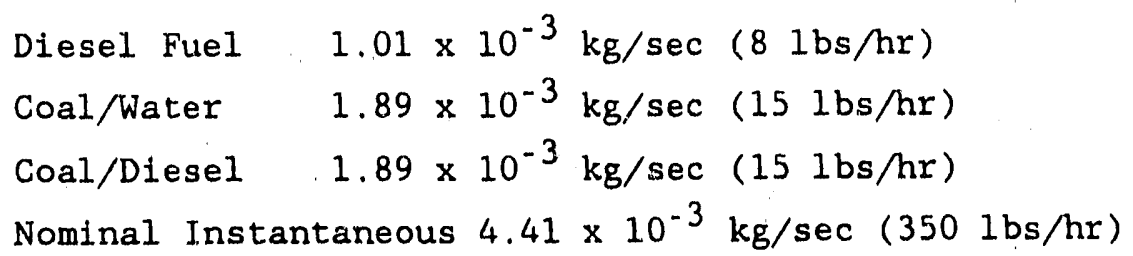

Flow Rate

Timing

Injector Valve Opens 25 degrees BTDC (Before Top Dead Center)

Injector Valve Closes 5 degrees ATDC (After Top Dead Center)

Nominal Injection Period 3 to $5 \mathrm{msec}$ (at $1000 \mathrm{rpm}$ )

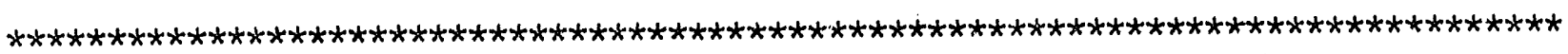

- Determination that vortex devices (for a detailed description of vortex devices see section 2.1) may have three important uses in slurry fuel feed systems:

Vortex devices may serve as no-moving-parts fluid interface valves in which "clean" fluids control "dirty" slurries. 
Bistable and proportional throtting characteristics of vortex devices appear relevant to the injection of cual slurry fuels into diesel engines.

Centrifugal pressuxe forces which are developed in a vortex chainber might be used to atomize the slurry more efficiently as it enters into the engine cylinder.

Identification of rortex flow throttling techniques that are applicable to the design of slurry vortex valves and slurry vortex swirl injector spray nozzles.

Analysis of concepts for fluidic fuel injector components and circuits for coal slurries.

Determination of viability of vortex devices including practical sizes for meeting minimum Reynolds number and maximum time response requirements over the anticipated viscosity range of the candiciate slurry fuels.

Completion of conceptual designs for fluidic fuel injector circuits using coal/water, coal/diesel, and coal/air fuels.

The fourth and fifth deliverable items were the Topical Report for Task II Laboratory Scale Testing, and the Prototype Test Plan developed during Task III - Prototype Test Plan. Per the requizements of the Management Plan as revised on October 20,1988, final versions of these two documents were delivered as a single submittal on February 15, 1989 (Ref. 3).

The Task. II Laboratory Scale Testing established a CWS test facility at Teknocraft's -aboratory in Palm Bay, Florida. The facility consisted of the following major items:

FMC triplex type ceramic slurry pump capable of pumping up to 5 gallons per minute of CWS at pressures up to 5000 psi. 
- CWS storage reservoir and plumbing system with provisions for purging all plumbing with clean water to avoid problems with CWS settling out in the plumbing between tests. The reservoir incorporated a propeller type fluid mixid to agitate and keep the mixture uniform.

- Twenty horsepower variable speed drive for the FMC pump to vary the CWS pump's output to control pressure and flow.

- Micro-Motion mass flow meter for measuring the CWS flow rate and density.

- Ventilated spray booth to enable continuous observation of CWS sprays in the atmosphere.

- Dynamic pressure instrumentation system for recording CWS and control signals in the fluidic components.

- Nitrogen bottles ali regulators to provide gascous control fluir at high pressure.

- A six plunger (diesel type) fuel pump and drive to provide high pressure liquid control fluids.

The design of the test equipment at Teknocraft and particularly the CWS storage and handling system were designed to avoid problems which had been encountered by other researchers using CWS. After encountering problems with the FMC pump at high pressures, a batch type CWS pumping system using bladder type accumulators was used.

As documented in the topical report, several types of fluidic components were Lested with the only successful components being the vortex valve and the vortex swirl nozzle.

The test program at Teknocraft accomplished its ultimate goal with the successful bench testing of a new component, hereafier referred to as the 
vortex throttling nozzle. A vortex throttlirg nozzle was nonstructed and operated in a manner simulating engine operation.

The last program task consisted of designing and fabricating fluidic injectors and using them to operate a coal-fueled diesel engine. The Caterpillar $1 Y 73$ engine at Adiabatics which had been used for research with other types of coal introduction systems was used for this program. Thrce different injectors were fabricated and tested on this engine.

\subsubsection{RESULTS AND ACCOMPLISHMENTS}

- The program has identified fluidic vortex swirl type noz $;$ to be particularly suited for atomizing coal-water slurry fuels. Atomization of standard engine grade CWS fuels was shown at pressures much lower than that normally associated with single and multi-hole injector nozzles.

- A novel approach for isolating the coal slurry fuel from close fitting injector components was identified which employs a clean fluid, i.e. liquid, gas or steam, flow to isolate the slurry fuel from close fitting injector valve components.

- Successful bench tests were conducted using either water or compressed air to control the flow of slurry fuel through a vortex throttling valve.

- A solenoid actuated, air controlled, vortex valve was successfully bench tested and tested on a medium speed single cylinder diesel engine using coal slurry fuel.

\subsection{TECHNICAL APPROACH}

The program identified several types of fluidic devices which are particularly applicable for use with coal slurry fuel. Previous topical reports have discussed various fluidic concepts and how they could be applied to an injection system. A single approach was selected to proceed from concept to engine testing. This concept is known as the Vortex Throttling Nozzle (VTN). 
The VTN combines, in a single component, the functions of a vortex type throttling valve and a vortex swirl nczzle. A review of the applicable technology and nomenclature for these three components are as follows:

\subsubsection{VORTEX SWIRL NOZZLE}

A ortex swirl nozzle consists of a swirl chamber, spin chamber, outlet port, and inlet port arranged as shirn in Figure 2. Slurry fuel enters the nozzle in a direction tangent to the edge of the swirl chamber. Beause of its direction of entry, the fluid attains a tangential velocity and forms a free vortex in the chamber. In a free vortex, angular momentum is conserved and angular velocity increases as the fluid swirls towards the center of the chambor. This produces a low static pressure in a region along the central axis of the nozzle chamber. Above a certain injection rate (determined by the properties of the fluid and the geometry of the nozzle) the static pressure near the center of the vortex falls below the static pressure on the outlet side of the nozzle. When this occurs hydrodynamic forces act to produce an air core that extends from the back surface of the spin chamber along the central axis of the nozzle througi the outlet. Here the pressure in the air core region is equal to the pressure on the outlet side of the nozzle.

\section{INPUT PORT}
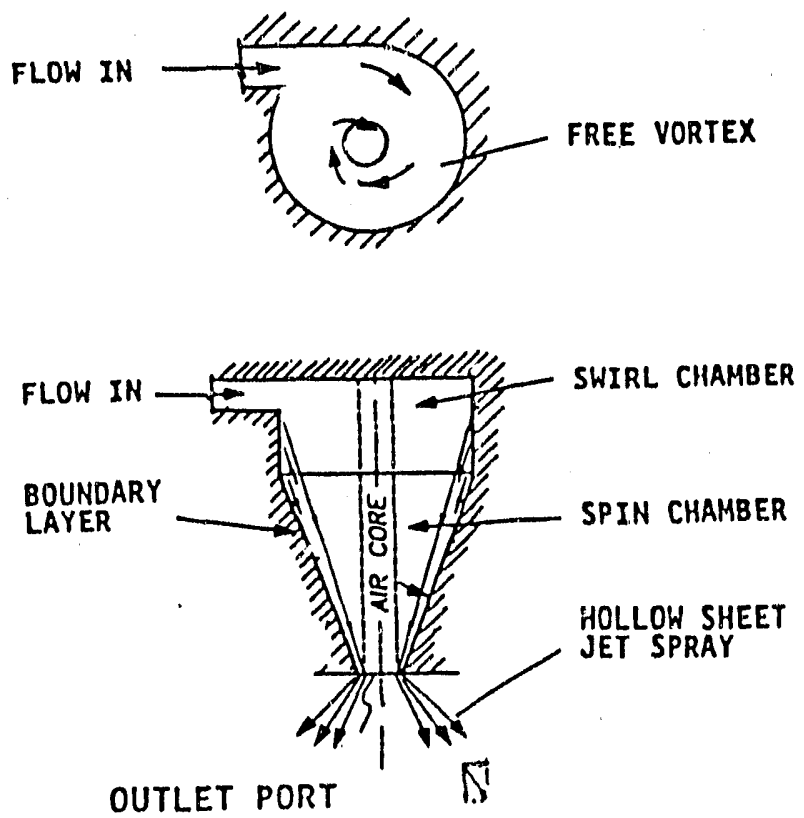

FIGURE 2. SWIRL NOZZLE 
Fluid leaves a swirl nozzle through the annular space that is formed between the air core and walls of the outlet. The diameter of the air core determines the width of the gap that is formed between the walls of the nozzle and the inner core boundary. The size of the air core has been reported by Som (ref. 4) to be related directly to inlet Reynolds number, chamber length, diameter, convergence angle and the outlet diameter of the nozzle.

The jet flow leaves the nozzle in the form of a hollow conical sheet (film) which breaks up into droplets downstream of the nozzle. The relative size of the air core and size of the nozzle determine the initial film thickness and nozzle discharge coefficient. The properties of the fluid, and tangential velocity components of the emerging jet determine the angle of divergence, and ultimately the size of the droplets that are formed by the fuel charge.

\subsubsection{THEORY OF SWIRL NOZZLE OPERATION}

As the fluid emerges a swirl nozzle the axial velocity component, $v_{a}$, tangential velocity component, $v_{t}$, and the static pressure inside the nozzle must satisfy Bernoulli's equation (1),

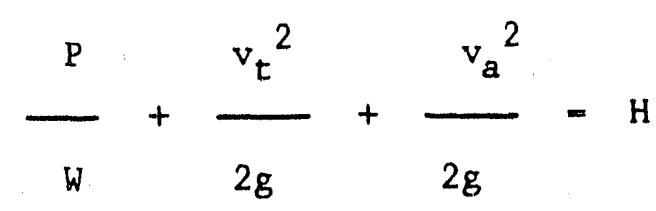

and the static pressure increases at a rate depending upon the distance from the nozzle axis as described by (2).

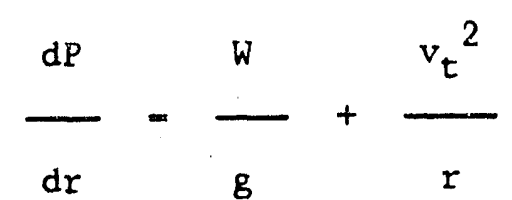

The air radius $r_{b}$ of the air core, is related to the axial velocity $v_{a}$ by the continuity equation

$$
\pi\left(r_{0}^{2}-r_{b}^{2}\right) v_{a}-\pi r_{i}^{2} v_{i}
$$

where $r_{i}$, and $v_{i}$, are the swirl nozzle outlet radius and velocity of the fluid respectively. 
The size of the liquid droplets produced by a swirl nozzle is primarily dependent upon the size (area) of the annular space that is formed between the air core and the walls of the outlet nozzle. The size (area) of tine air core is determined by the geometry of the nozzle chamber, ratio of the tangential t:o axial velocity, and the viscosity of the fluid (4).

$$
D_{\text {smd }}=f\left(D_{1}, D_{2}, 2 \alpha, \rho, \mu, v_{a}\right)
$$

Using the results of many measurements of mean drop dianeter, viscosity, and nozzle geometry Som derived the semi-empirical relationship (5),

$$
\frac{\mathrm{D}_{\text {smd }}}{\mathrm{D}_{2}}=\mathrm{K}_{1}\left(\mathrm{~N}_{\mathrm{ro}}\right)^{\mathrm{K}_{2}}\left(\mathrm{D}_{2} / \mathrm{D}_{1}\right)^{\mathrm{K}_{3}}(2 a)^{\mathrm{K}_{4}}
$$

where values of constants, $K_{1}, K_{2}, K_{3}$, and $K_{4}$ were determined from experimental data by a standard least squares method from which $\mathrm{K}_{1}=0.625$, $K_{2}=-0.731, K_{3}=-680$, and $K_{4}=-530$. It should be noted that Reynolds number, $\mathrm{N}_{\text {ro }}$, is defined by the outlet port diameter, $\mathrm{D}_{2}$, and the velocily, $\mathrm{v}_{\mathrm{a}}$. However, because of the formation of the central air core inside the vortex swirl nozzle, the effective flow area of the outlet port is less than that based on $D_{2}$. Because of this, the relationship that Som uses to express $\mathrm{N}_{\text {ro }}$ is based on measured flow rate given by (6)

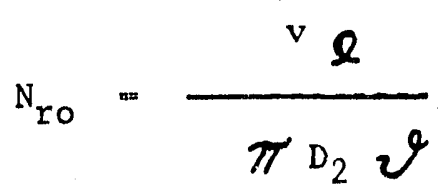

Curves illustrating calculated values of mean drop diameters are shown as Figure 3 .

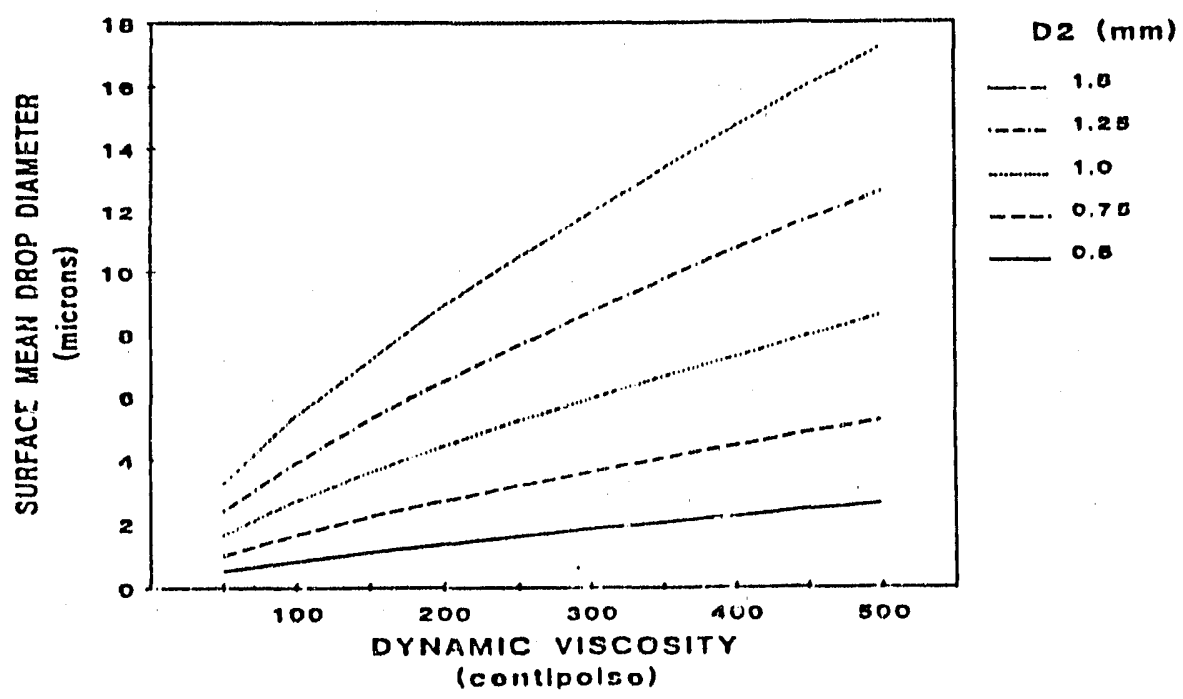

FIGURE 3. SAMPLE CALCULATIONS OF MEAN DROP DIAMETERS 


\subsubsection{VORTEX THROTTLING VALVE}

A vortex throttling valve is fundamentally a variable flow restrictor without moving parts which is ablo to approximate the flow characteristics of a mechanical valve. The flow geometry of a voitex valve is shown in Figure 4. The valve is comprised of a cylindrical vortex chamber, two inlets called the supply port and the control port, and an outlet port.

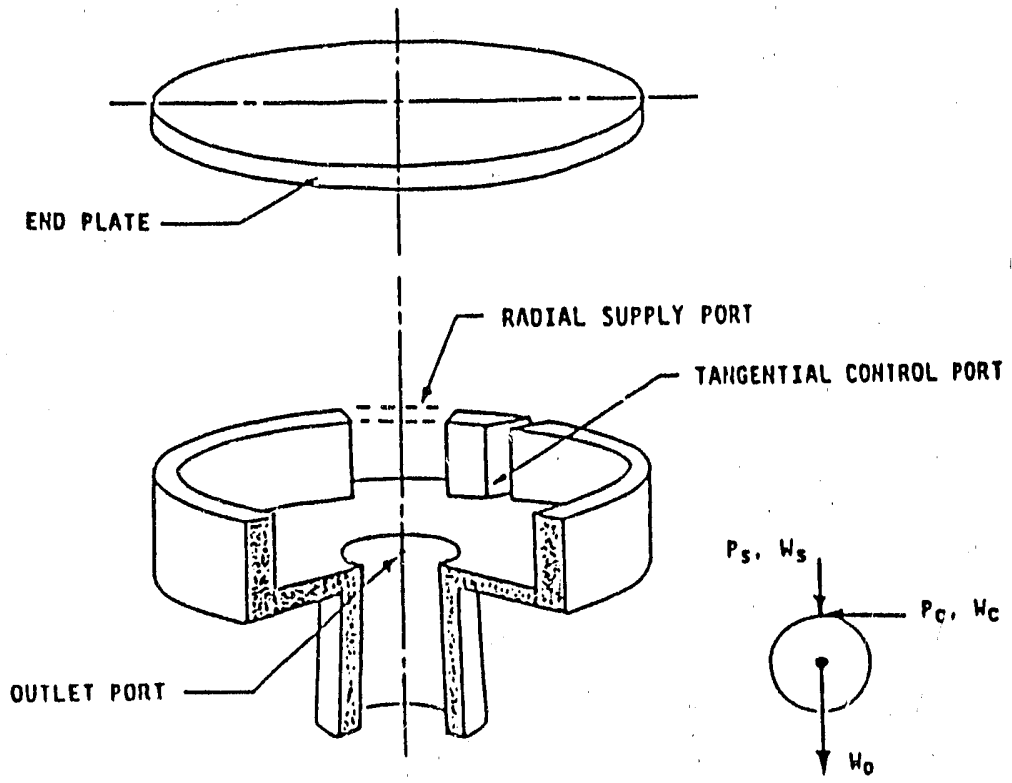

FIGURE 4. FLUIDIC VORTEX THROTTLING VALVY

Without control flow, $W_{c}$, the supply fluid, $W_{s}$, passes directly through the vortex chamber at a rate determined primarily by the supply pressure and the area of the outlet. Since there is no vortex in the chamber, the supply flow is at its maximum level. When the pressure in the control port, $P_{c}$, is raised above the supply pressure, $P_{s}$, control flow enters the vortex chamber and imparts a rotational component to the supply flow. 'Ihis interaction creates a free vortex in the chamber. If the supply pressure is held.constant, increasing the control pressure increases centrifugal pressure forces which act to reduce the supply flow to zero. At zero supply flow only the control flow is flowing.

The ratio between the naximum fuel flow rate when the control flow is zero to the control flow rate at which it reduces the fuel flow to zero is called the turndown ratio. The turndown ratio is used as a measure of the valve $s$ throttling effectiveness. Turndown can be bistable (on-off) or proportional to the control flow depending upon the vortex chamber geometry. The amount of 
flow needed to produce full turndown of the supply flow is usually 5-15 times less than the maximum fuel flow before turndown. The relative amount of control fluid required to produce turndown depends primarily upon the geometry of the vortex chamber and viscosity of the fluid. The time to produce turndown is a function of the empty/fill time of the vortex chamber which is equal to the chamber volume divided by the volumetric flow rate.

Vortex valve operating characteristics are illustrated by the curves contained in Figure 5. Here it can be seen that the response of a vortex valve can be proportional or bistable. In each case the ratio between the maximum supply Hlow rate when the control flow is zero to the control flow rate at the cutott point is called the turndown ratio. The turndown ratio is a number that is used as a measure of the valve's throttling effectiveness. The bistable and proportional operating characteristics of a vortex valve are determined by the geometry of the vortex chamber. The relative amount of fluid required to produce turndown depends primarily upon the ratio between the inner and outer radii of the vortex chamber and the viscosity of the fluid. The time to produce turndown is determined by the empty/till time of the vortex chamber which is equal to the chamber volume divided by the volumetric flow rate.
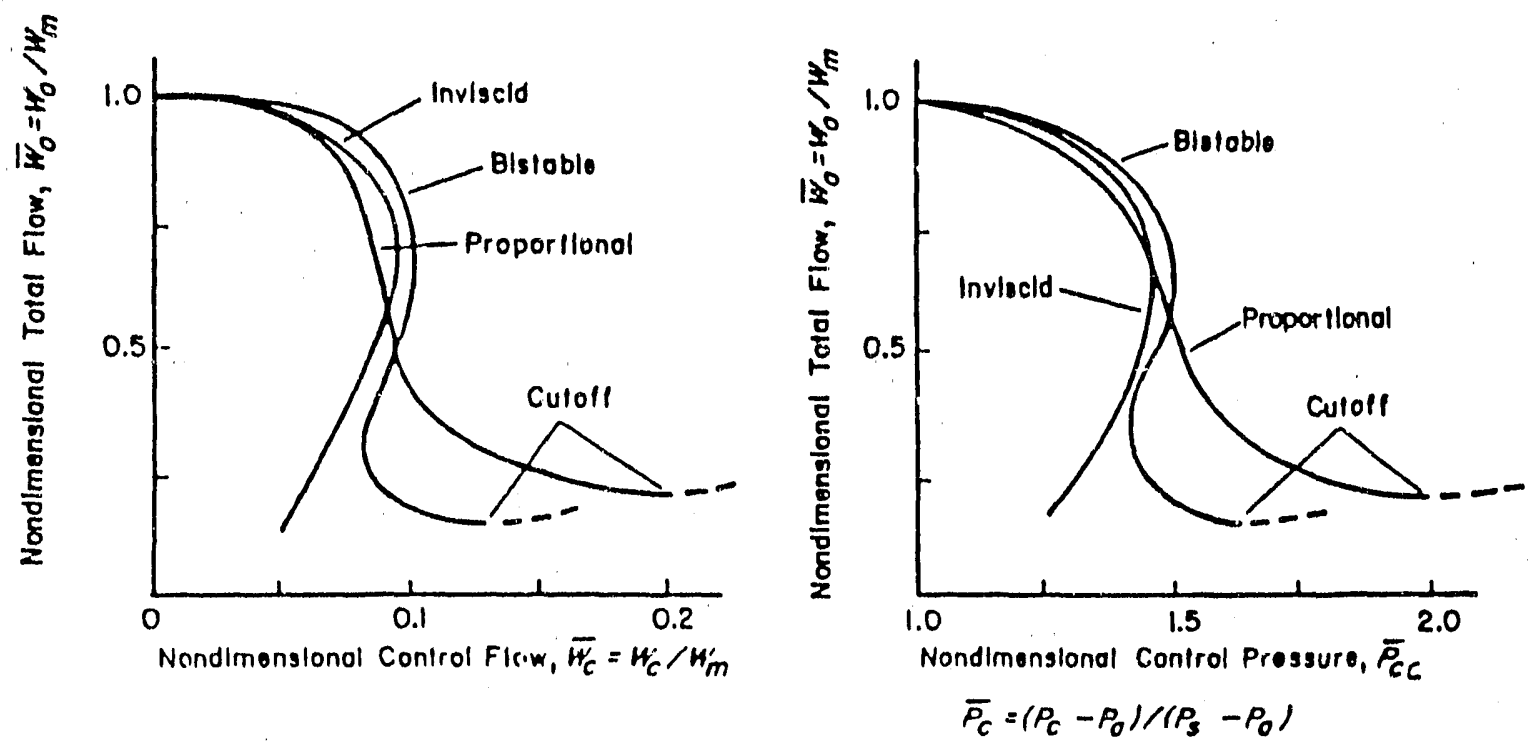

FIGURE 5. VORTEX VALVE OPERATING CHARACTERISTICS (WORMLEY, reference 5 ) 


\subsubsection{THEORETICAI OPERATION OF VORTEX VALVES}

The functional characteristics of vortex valves anc swirl nozzles as well, depend primarily upon the change in tangential velocity that takes place between the inner and outer edge of the flow field that is produced inside the vortex chamber. The change in volocity that o:curs is a function of the chamber geometry and the viscosity of the fluid. When the viscosity of the fluid is low, a "free" vortex is produced in the chamber. In a free vortex, angular momentum of the fluid is conserved and the change in tangential velocity that is produced in the chamber i.s inversely proportional to the radial location in the chamber such that (7)

$$
v_{t}=v_{t o}\left(\frac{r_{0}}{r}\right)^{n}
$$

where $n=1$ for a free vortex. When the effects of viscosity are present fluid motion in the vortex chamber is retarded and a maximum tangential velocity is reached as the fluid approaches the center of the chamber.

The corresponding differential pressure forces that are produced between the slower (higher pressure) fluid particles at the outer edge of the vortex and the faster moving (lower pressure) fluid particles near the center of the vortex can be expressed as (8)

$$
d P=\frac{v_{t}^{2} \nu^{d} d r}{r}
$$

where $\mathcal{f}$ is the fluid density and $\mathrm{dP}$ is the differential pressure across a differential radial element dr. From equation (7) and (8) follows:

$$
d P=\rho\left(\frac{v_{t o}{ }^{2}}{r}\right)\left(\frac{r_{0}}{r}\right)^{2 n} d r
$$


For incompressible flow, the pressure at any radius, $r$, is given by (10)

$$
P=\frac{\left(-\rho v_{t o}^{2} r o^{2 n} r^{2 n}\right)}{2 n}+c
$$

where $C$ is a constant (11).

$$
C=p_{0}+\frac{\rho v_{t 0^{2}}}{2 n}
$$

Analysis by Wormely (reference 5 ) and others have shown that the turndown characteristics of a vortex valve are only a function of two non-dimensional ratios, $A_{s} / A_{e}$ and $r_{e} / r_{0}$, when appropriate valves of area ratios, $A_{c} / A_{e}$, and chamber height ratios $h / r_{e}$ are employed. The relationship between radius ratio $r_{e} / r_{0}$, and other geometrical parameters are illustrated in the Wormely design curves contained in reference 5 .

\subsubsection{VORTEX THROTTLING NOZZLE}

A vortex throttling nozzle is a combination vortex valve and swirl nozzle. Figure 6 describes the principal features of a vortex throttling nozzle. In a vortex throttling nozzle the functions of each component have been combined in order to reduce circuit volume and, therefore, reduce response time. A vortex throtting nozzle is similar to a vortex valve in that it consists of a vortex chamber, control port, outlet port, and a fuel port. However, as in the swirl nozzle, the supply port is offset to one side of the vortex chamber to produce a vortex flow. Because of its tangential entry, the fuel forms a free vortex in the chamber and emerges from the nozzle in the form of a hollow conical sheet. The relative location of the entry port relative to the radial centerline and the entrance velocity and Reynolds number determine the drcplet size, cone angle and overall characteristics of the jet spray pattern.

\subsubsection{SLURRY FUEL CONTROL CIRCUITS}

Previous studies conducted during the course of this contract have focused on 


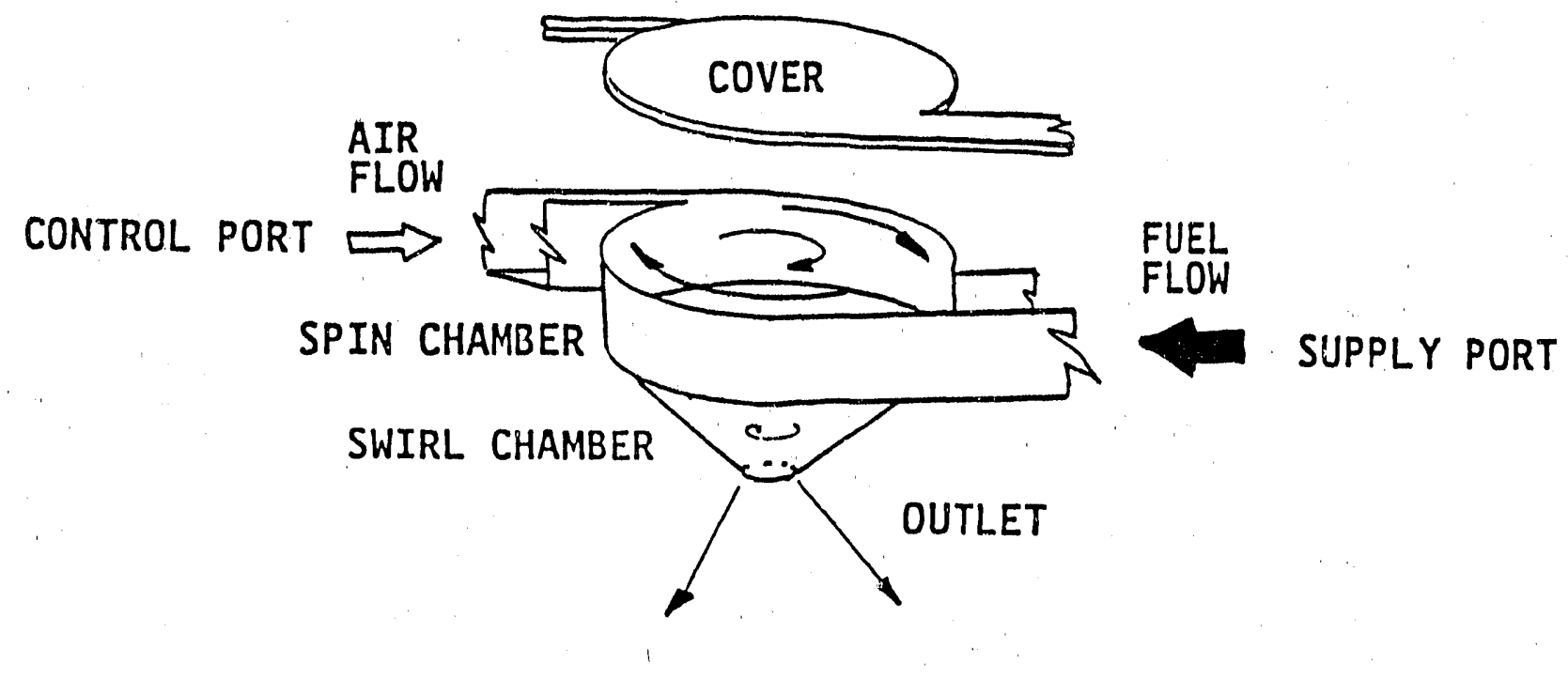

FIGURE 6, VORTEX THROTTIING NOZZLE

establishing various approaches to slurry fuel control circuit design (Holmes, ref. 6). As a result of these studies, two slurry fuel control circuits were selected for evaluation. The first circuit employed a solenoid-actuated vortex throtting nozzle in a rail type fuel distribution system. The second employed a biased vortex throttling nozzle in a jerk pump type system. Since the second system only required a high performance diesel type slurry pump with timed high pressure and short duration CWS pulses as output and involved fluidics only for the injector nozzle (and not for any injection control), the rail type system with solenoid valve control of the injection was selected for engine testing.

In the rail system shown in Figure 7 , the fuel slurry was supplied to the throttling nozzle from a pressurized accumulator. Compressed air was supplied from an engine-driven compressor through a solenoid valve to the control port of the throttling nozzle to control the on/off time of the fuel flow. The solenoid valve was actuated by timing signals generated in the electronic control module, which in turn received its signals from a sensor on the engine timing cam. The injection process was initiated when the solenoid valve was closed which stopped the compressed air flow which turned off the vortex. The fuel flow rate was controlled by a regulator which delivered air pressure to the accumulator. The injection period ended when the solenoid valve was opened and a vortex was produced by the control air. 


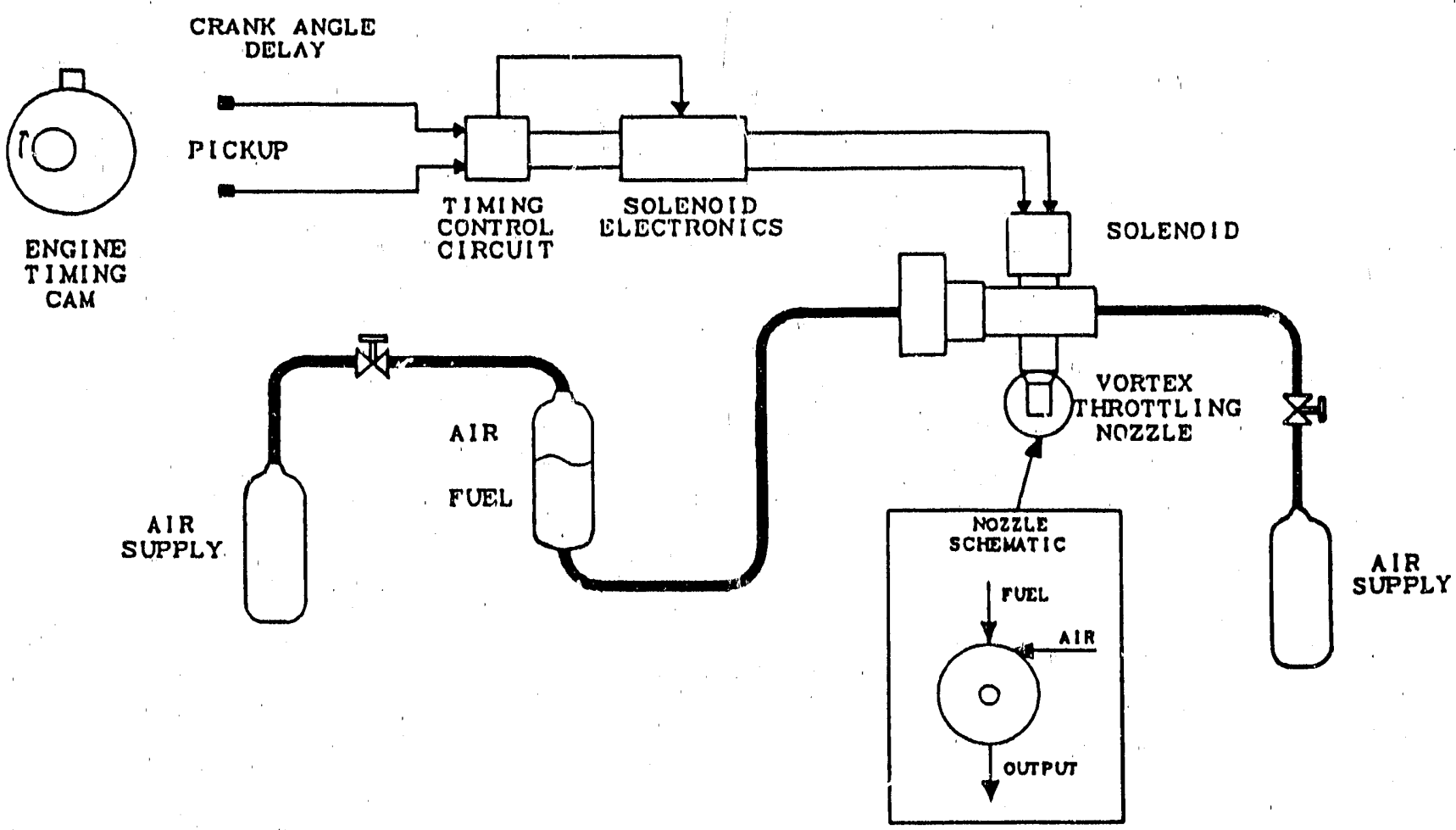

FIGURE 7. CIRCUIT ILLUSTRATING A SOLENOID-ACTUATED VORTEX THROTTLING NOZZLE IN A COMMON RAIL TYPE FUEL DISTRIBUTION SYSTEM

\subsection{TEST FACILITY DESCRIPTION}

During the last year, testing was transitioned from Teknocraft's facility in Palm Bay, Florida to Adiabatics in Columbus, Indiana. During this transition it was necessary to maintain a minimal test capability at Teknocraft so that they could test completed injector assemblies before shipment to Adiabatics for engine tests. The new facility at Adiabatics consists of the following: a coal slurry handling and pumping system which provided CWS at pressures up to 5,000 psi; a high pressure air supply system; an electronics control package (to control. the injector in synchronization with the engine); and an instrumentation system to measure pressures, flows and temperatures.

2.2.1 COAL SLURRY SYSTEM - Figure 8 is a schematic of the coal-water slurry handling and pumping system. This newest slurry handling system was designed 
to eliminate known problems and provide us with a dependable source of coal slurry with minimal maintenance. The system worked well and was trouble free. The slurry was stored in a conical tottom fiberglass tank with a discharge fitting at the bottom of the cone. From here the slurry flowed into a triplex type positive displacement pump with a variable speed motor control and normally back to the tank to provide recirculation and mixing. The actual high pressure pumping system uses a bladder type accumulator as a batch type pump. To fill the accumulator a series of valves were opened which connected the outlet of the triplex pump to the accumulator. The valve allowing the CWS to recirculate back to the tank was then throttled to provide the pressure to completely fill the accumulator (200 to $300 \mathrm{psi}$ ). A city water connection and a series of valves were provided to enable the triplex and accumulator pump systems to be flushed without disturbing the CWS in the tank.

2.2.2 AIR SUPPLY SYSTEM - The selected injector concept required a source of air at a pressure twice as high as the slurry pressure. To provide this

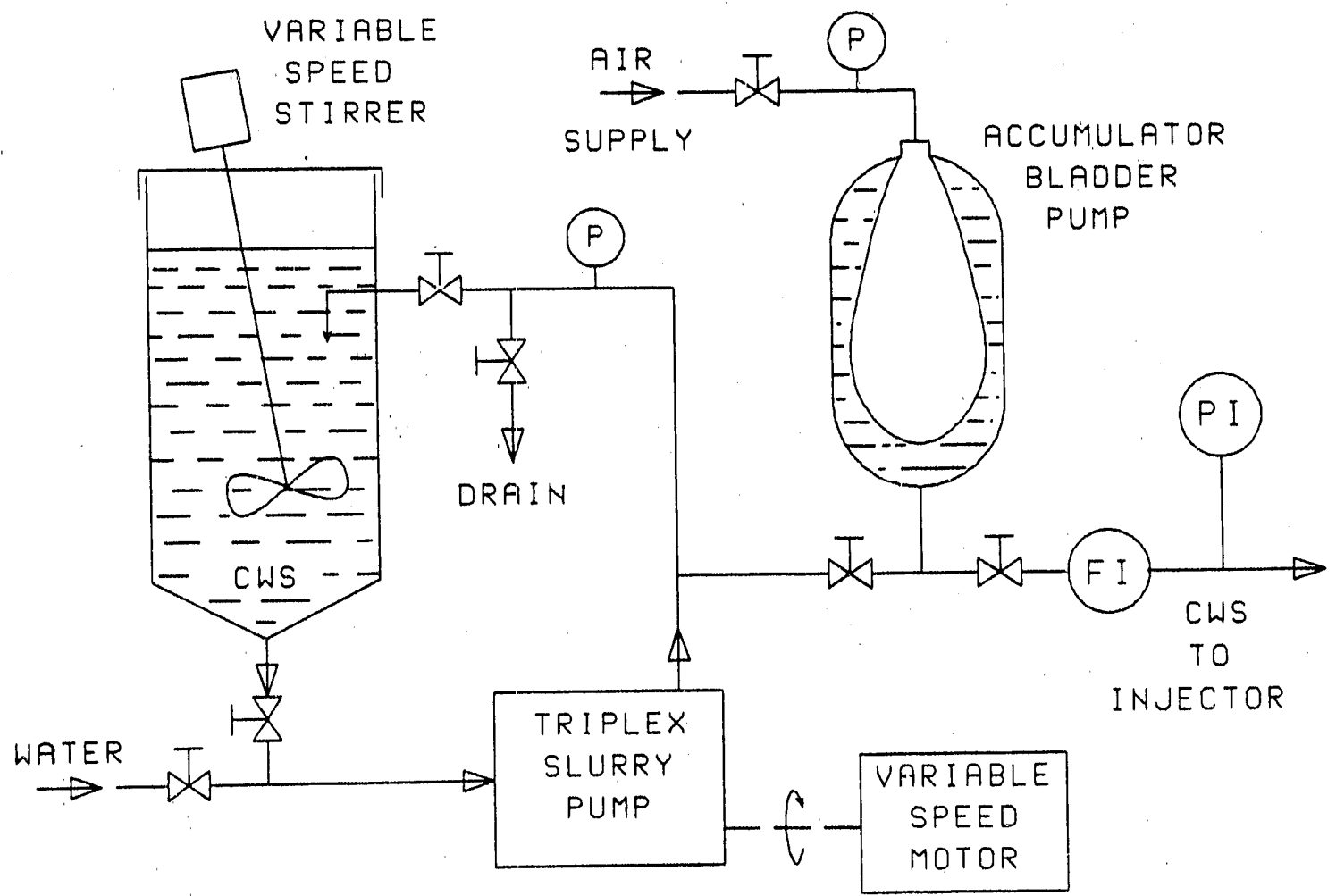

FIGURE 8. CWS HANDLING SYSTEM 
pressure an existing natural gas compression system was modified to provide air at pressures up to 5,000 psi as shown in Figure 9. Besides providing control air, this system also provided the pressure to drive the accumulator pump for the CWS.

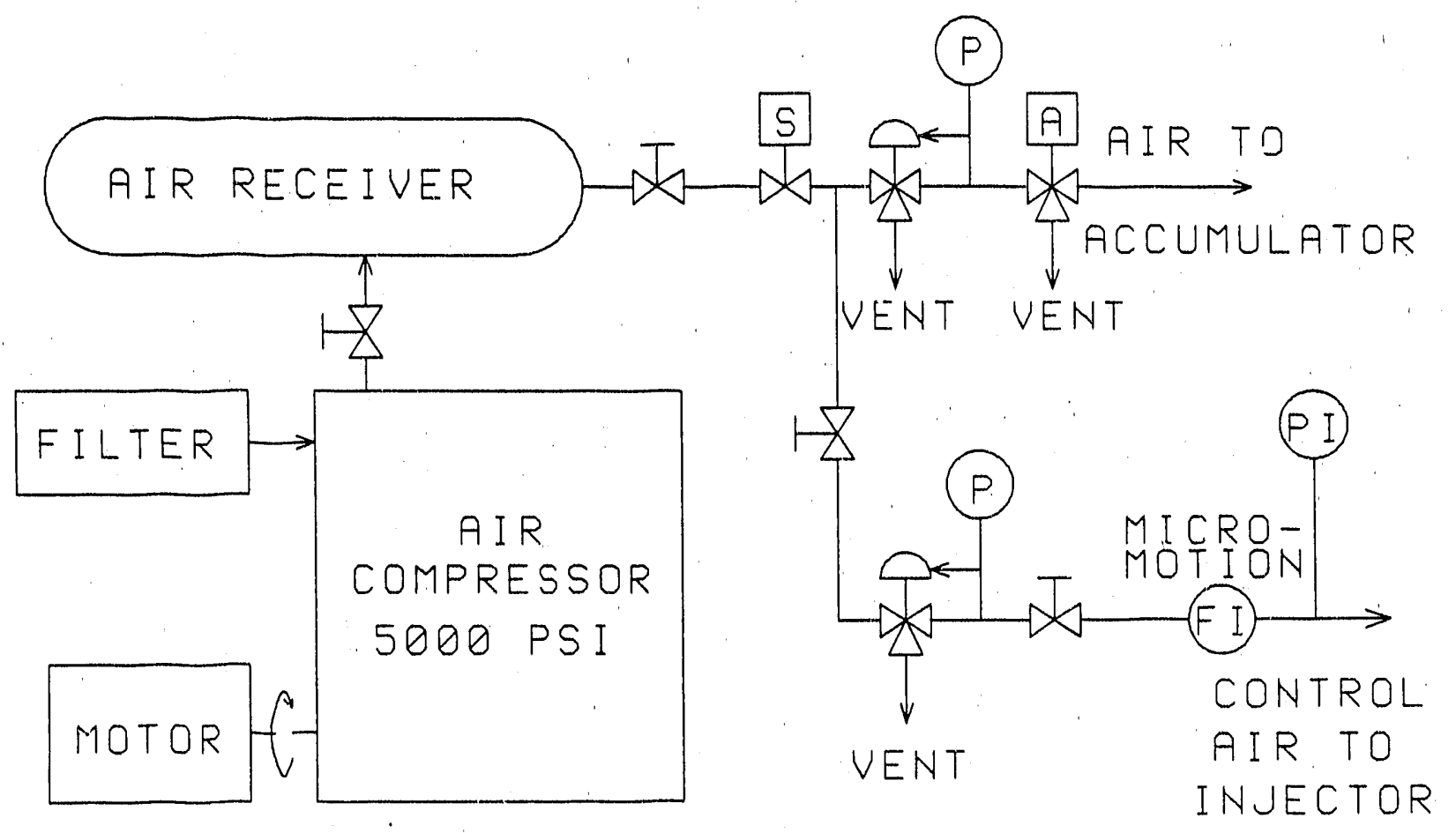

FIGURE 9. AIR SUPPLY SYSTEM

2.2.3 INJECTOR DRIVE ELECTRONICS - Figure 10 is a schematic of the driving circuitry for the injector solenoid. This system was triggered by a crankshaft position sensor on the engine and consisted of a delay circuit which was used to control injection timing, a pull in circuit that rapidly opens the solenoid, and a duration control circuit that times the length of the injection pulse.

2.2.4 TEST ENGINE - The CWS test engine is a single cylinder Caterpillar model $1 Y 73$ which was modifled to run without cooling and used an elevated temperature precombustion chamber. Figure 11 is a sketch of the details of these modifications. 
22.5 INSTRUMENTATION - The fluidic injector and auxiliary test equipannt were equipped with instrumentation to record the flow rates and dynamic pressures of both the control air signal and the CWS. The engine was instrumented with a crankangle encoder for accurate crank position determination and a fast response cylinder pressure transducer. These signals were fed to a high speed data acquisiticn system which recorded the synchronized crank position and cylinder pressure data and executed datı reduction programs to generate instantaneous rate of pressure rise and hest release curves. The engine was also instrumented with standard temperature and pressure instrumentation which was recorded on a computer based data logging system.

\subsection{FLUIDIC INJECTOR HARDWARE}

The basic fluidic injector consisted of a vortex throttling nozzle (VTN) and a high speed valve which shut off the control air to inject cWS into the engine. There was only one moving part in the control air valve and there were no moving parts in the VTN. Figure 12 is a simplified schematic diagram of the injector showing the solenoid operated air valve and the vTN.

obtaining an adequate ligh performance solenoid operated control air valve was the key pacing component in testing a complete injector assembly. The air valve was normally open and must be closed to start the fuel injection and opened to end the injection. The valve must be able to close and open again in times as short as one millisecond for high speed, low load conditions. Several normally closed solenoid operated valves were developed which could open quickly and then close but they were not adaptable for use as normally open valves. Because of the critical requirements for this component and since it is not available comme cially, a primary design was selected with a solenoid valve especially oesigned for this application. Backup designs using available components were also developed. The first backup design (\#1) was a bit of a Rube-Goldburg approach which used a normally closed solenoid pilot-operated valve and an additional valve assembly to invert the pilot valve signal into a normally open valve function (Figure 13). 


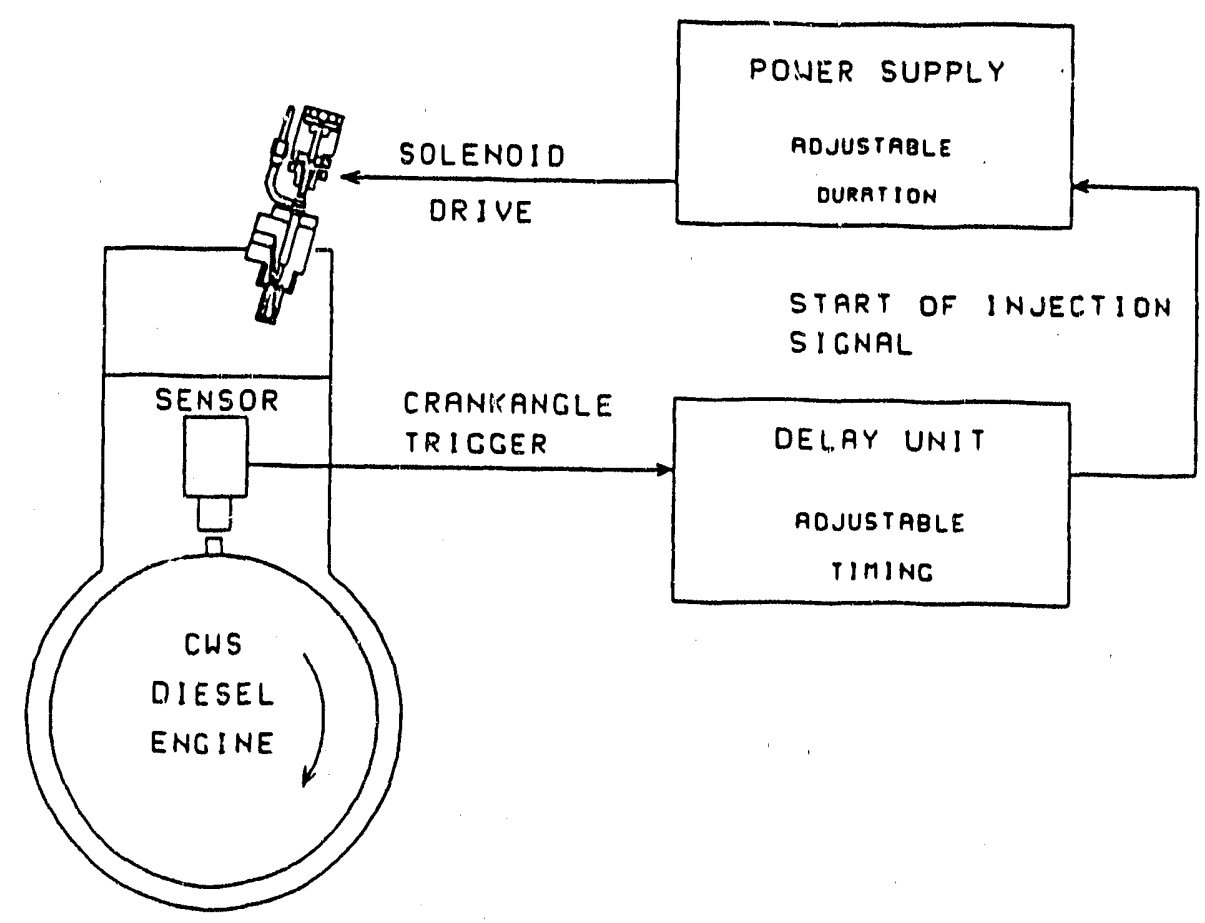

FIGURE 10. INJECTOR ELECTRONICS

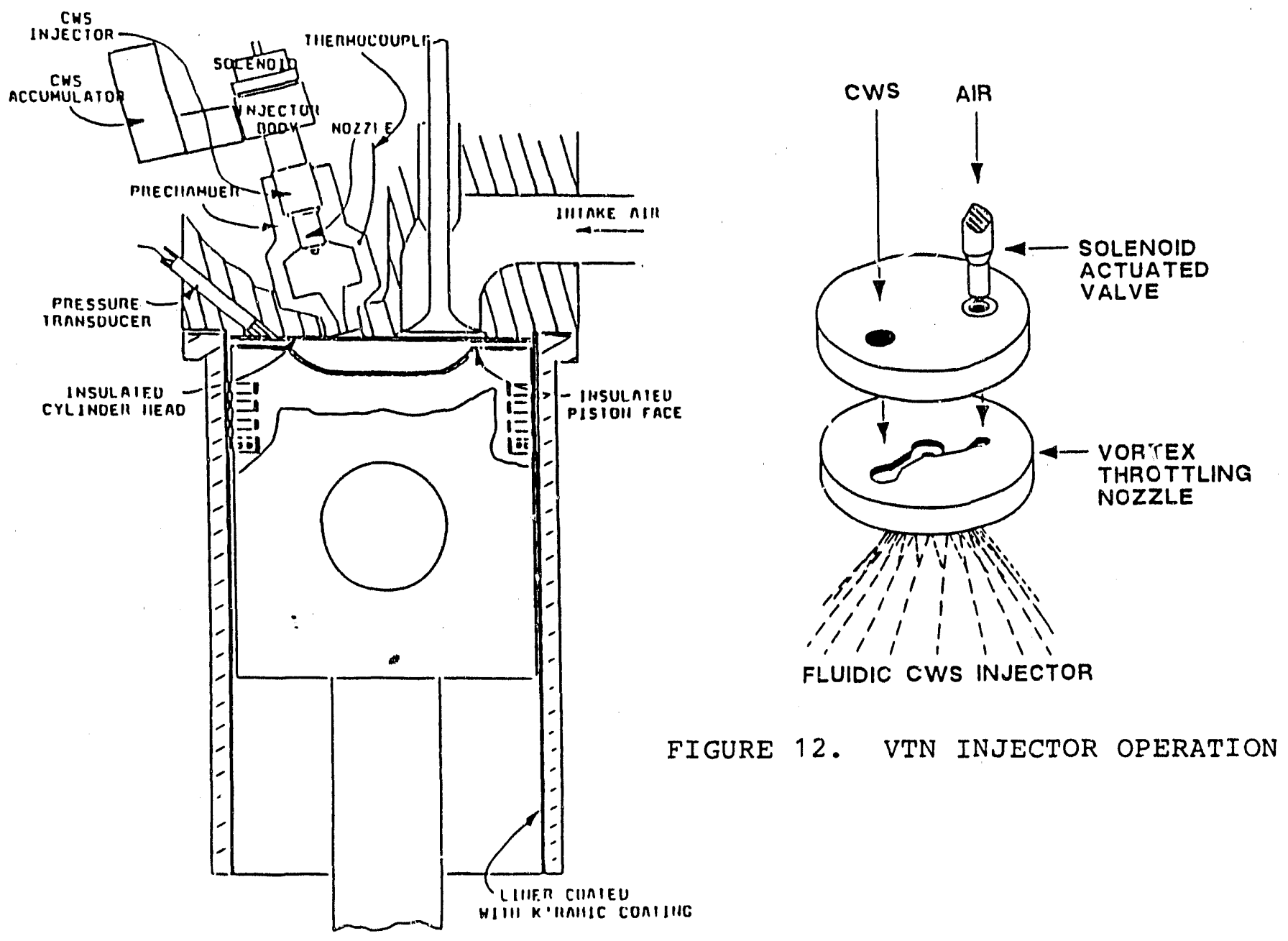

FIGURE 11. TEST ENGINES MODIFICATIONS 


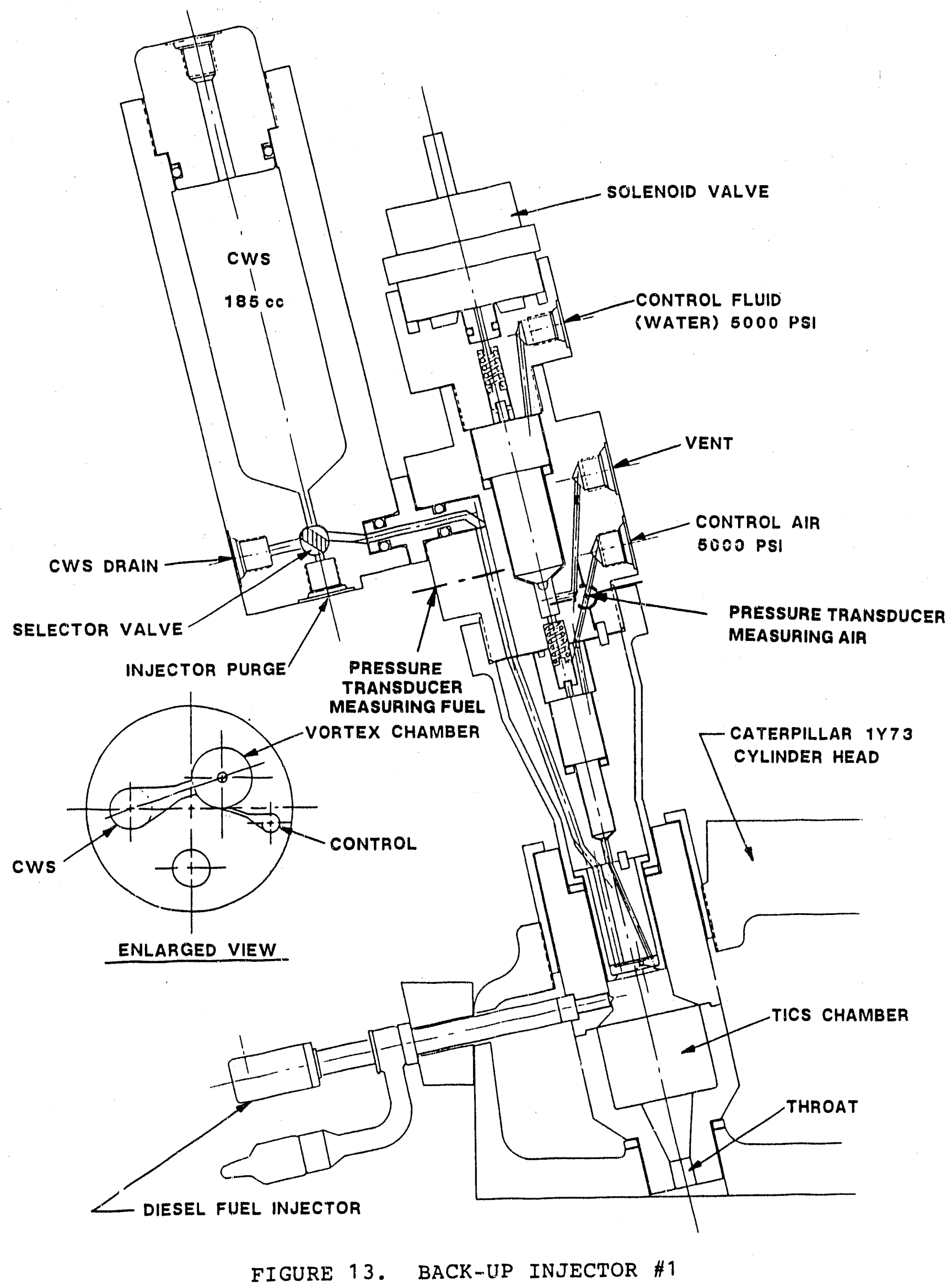


The second backup injector (非) used an available high speed solenoid coupled to a standard diesel type fuel injector to make a normally open valve assembly (Figure 14). With this approach, there was a small amount of air that leaked past the seal portion of the injector reedle which was vented to prevent the solenoid assembly from being pressurized.

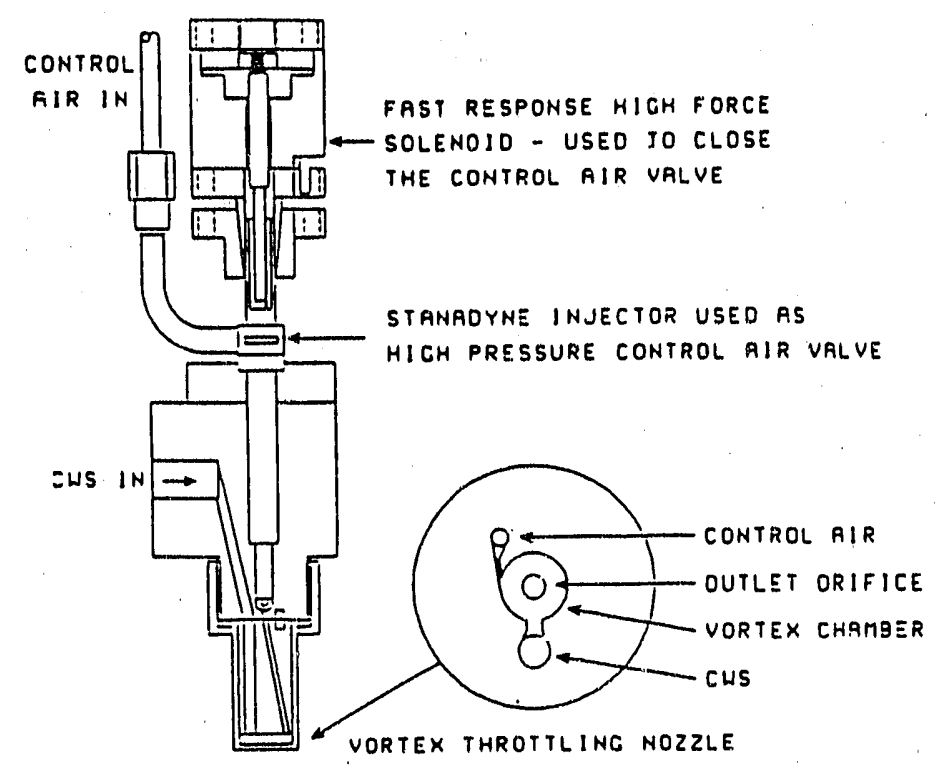

FIGURE 14. BACK-UP INJECTOR \#2

The Primary injector ( 3 ) design (Figure 15) used a sealed, pressurized solenoid valve assembly. This approach eliminated the need for a seal between the high pressure control air and the solenoid. This approach also eliminated the expensive, close fitting guide portion of the valve which made it possible to design the injector without rubbing parts by using a flexure support for the valve.

\section{3.) BENCH TEST RESULTS}

All three of the fluidic injectcrs were bench tested using both water and CWS as the injected fluid. The following is a summary of the bench testing conducted at Adiabatics for each of the injectors: 


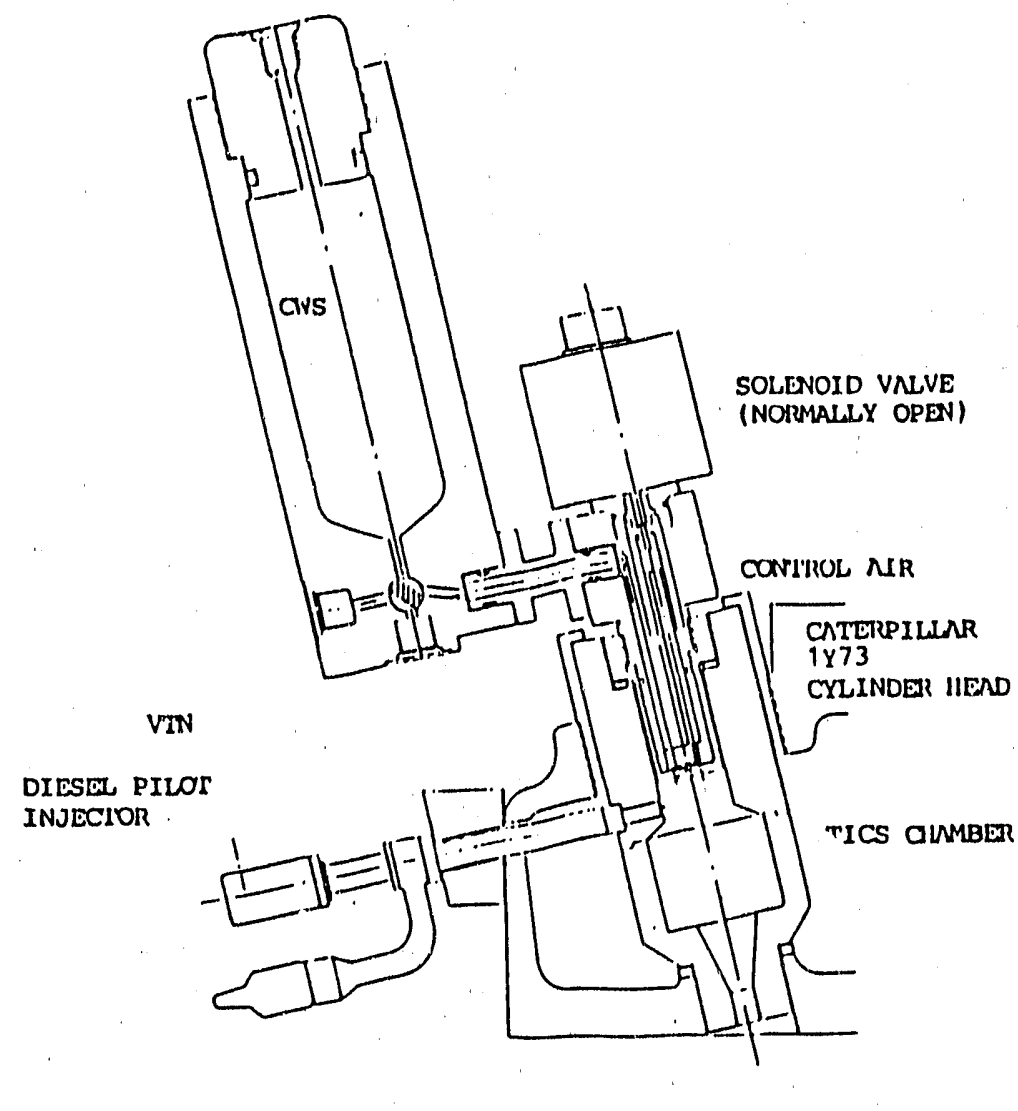

FIGURE 15. PRIMARY INJECTOR DESIGN \#3

The first injector tested was the servo actuated backup injector (非). The first testing used water rather than CWS as the injected fluid. This initial testing concentrated on developing techniques for starting the fluidic system from rest. This injector had three fluids to control. The first was servofluid which was used to close the control air valve. The second fluid was control air. The third was the injected fluid (water or CWS). Initially the nozzle was started by applying servofluid pressure and then actuating the servo system by pulsing the solenoid valve. Next the water/CWS was turned on followed by control air. Using extreme care the injector did pulse for a short time. However, the infection would fall by either solid injection of water/CWS (the term solid injection is used to describe continuous injection and atomization of water/(WS) or else control air would back up into the water supply line and stop the injection. Figure 16 is a recording of the servo pressure acting on the top of the control air valve and the pressure in the CWS accumulator. The curve showed that the servo system was working and that the control air pressure built up and decayed quickly. There was a corresponding drop in CWS pressure during the injection period which was very repeatable. When working properly, the injections from this injector were very consistent and the injector operated well over large pressure and flow ranges. However, the duration of the injection was too long to use it for engine testing. 


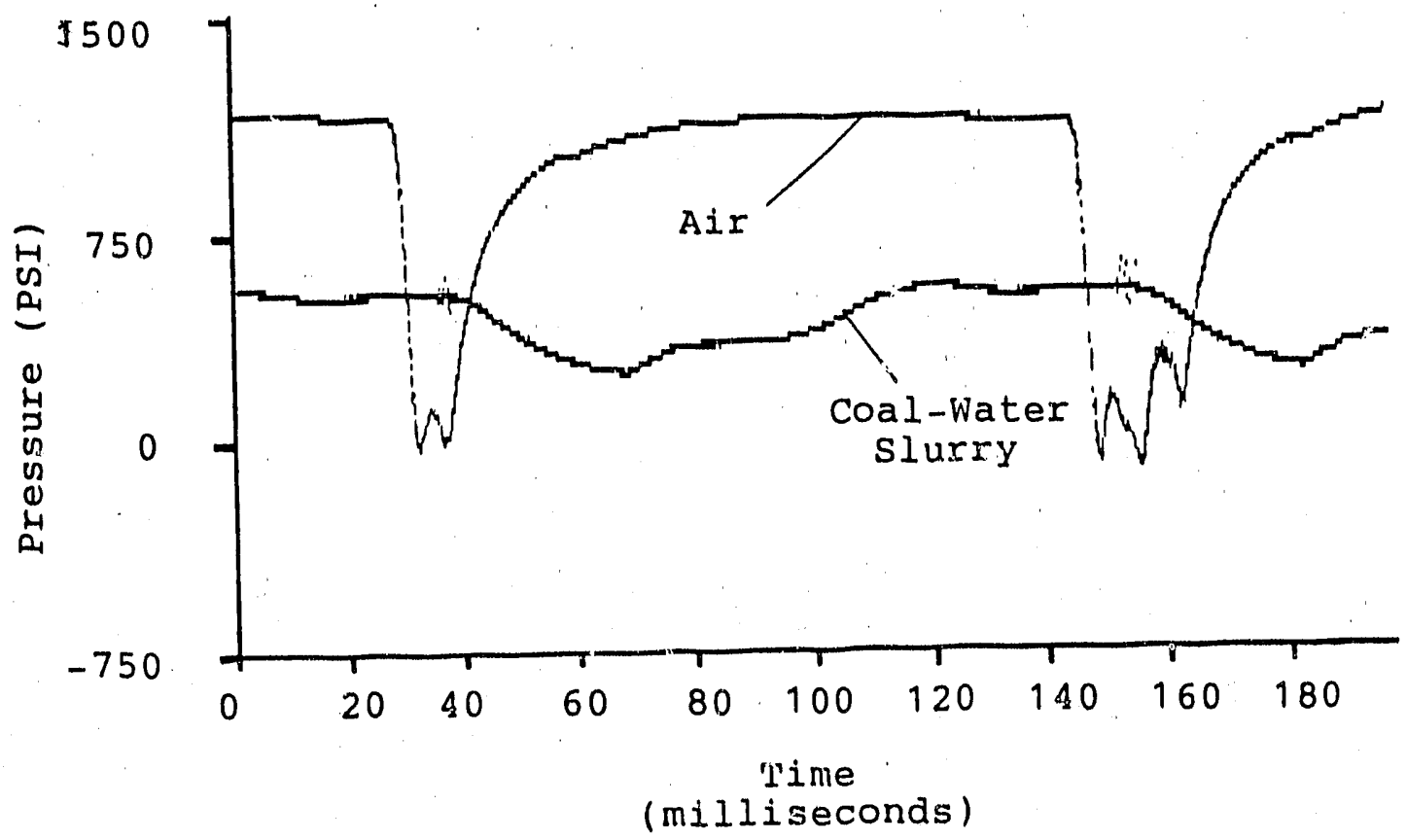

FIGURE 16. BACK-UP \#1 PERFORMANCE

Backup injector $\# 1$ was tested with a modification to provide a larger passage for control air in an attempt to shorten the injection duration without success. Previous diagnostic tests revealed that control air was leaking past the servovalve plunger into the servofluid causing an emission of the two fluids to form which resulted in the servofluid becoming quite spongy and slow to react. The injector was then modified to introduce a leak-off path for the control air part way up the servovalve plunger. The size of the spill orifice was increased to enable the servofluid pressure to decrease faster and thus shorten the control air pulse duration. Testing with this combination showed that the problem was not solved and that the air was still leaking into the servofluid which resulted in long durations. During this testing tna expansion of control air into the vortex chamber would cause the chamber to cool excessively. This caused the prechamber to fill with ice. The problem was solved by installing an electric heater which was positioned to heat the nozzle end of the injector.

Backup injector 非 with direct solenold actuation of the control air valve was bench tested and documented that it was able to achieve very short durations of air turnoff which should have resulted in short injection durations. However, this injector was not able to inject any water at any reasonable combination of: pressures. If the water pressure was increased to be in the same range as control pressure, the injector would flow a continuous stream of water. Occasionally the injector would act properly but would quickly revert to flowing either all air or all watex. In an attempt to eliminate this problem 


\begin{tabular}{|c|c|c|c|c|c|}
\hline VERSION & $\begin{array}{l}\text { OUTLET } \\
\text { DIAM. }\end{array}$ & $\begin{array}{l}\text { CHAMBER } \\
\text { HEICHT }\end{array}$ & $\begin{array}{l}\text { CONTROL } \\
\text { WIOTH }\end{array}$ & $\begin{array}{l}\text { CHAMBER } \\
\text { DIAM. }\end{array}$ & $\begin{array}{l}\text { SUPPLY } \\
\text { WIDTH }\end{array}$ \\
\hline & $\begin{array}{l}0.030 \\
(0.75)\end{array}$ & $\begin{array}{c}0.030 \\
(0.76)\end{array}$ & $\begin{array}{l}0.010 \\
(0.25)\end{array}$ & $\begin{array}{l}0.210 \\
(5.33)\end{array}$ & $\begin{array}{l}0.050 \\
(1.27)\end{array}$ \\
\hline F & $\begin{array}{l}0.030 \\
(0.76)\end{array}$ & $\begin{array}{c}0.020 \\
(0.51)\end{array}$ & $\begin{array}{c}0.010 \\
(0.25)\end{array}$ & $\begin{array}{c}0.210 \\
(5.33)\end{array}$ & $\begin{array}{l}0.050 \\
(1.27)\end{array}$ \\
\hline & $\begin{array}{c}0.040 \\
(1.02)\end{array}$ & $\begin{array}{c}e .020 \\
((0.51)\end{array}$ & $\begin{array}{c}0.010 \\
(0.25)\end{array}$ & $\begin{array}{c}0.210 \\
(5.33)\end{array}$ & $\begin{array}{l}0.050 \\
(1.27)\end{array}$ \\
\hline 7 & $\begin{array}{l}0.030 \\
(0.75)\end{array}$ & $\begin{array}{l}0.325 \\
(2.54)\end{array}$ & $\begin{array}{l}0.006 \\
(0.15)\end{array}$ & $\begin{array}{l}0.240 \\
(6.10)\end{array}$ & $\begin{array}{l}0.040 \\
(1.02)\end{array}$ \\
\hline$E$ & $\begin{array}{l}0.030 \\
(0.7 E)\end{array}$ & $\begin{array}{l}e .8 \geq 5 \\
(\varepsilon .54)\end{array}$ & $\begin{array}{l}0.006 \\
(0.15)\end{array}$ & $\begin{array}{l}0.240 \\
(6.10)\end{array}$ & $\begin{array}{l}0.040 \\
(1.02)\end{array}$ \\
\hline$r$ & $\begin{array}{c}0.030 \\
(0.75)\end{array}$ & $\begin{array}{l}0.830 \\
(0.76)\end{array}$ & $\begin{array}{l}0.010 \\
(0.25)\end{array}$ & $\begin{array}{l}0.420 \\
(10.7)\end{array}$ & $\begin{array}{l}0.050 \\
(1.27)\end{array}$ \\
\hline
\end{tabular}

FICURE 17. VTN GEOMETRIES

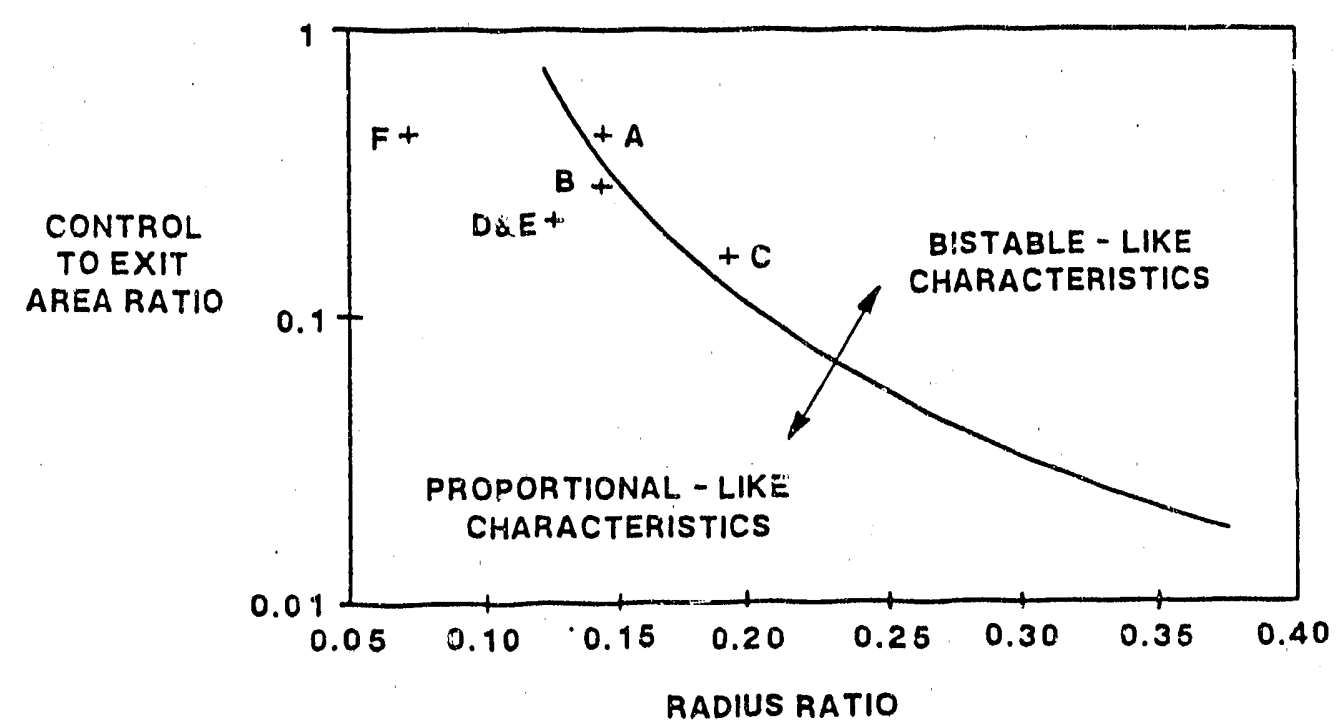

FIGURE 18. VORTEX VALVE 
four additional fluidic vortex throttling nozzle geometries were tested to determine if this problem could be eliminated. Figure 17 shows the geometries of the different designs. Figure 18 is an empirically derived plot which was used to design vortex valves, specifically to predetermine whether a given vortex valve geometry will be proportional or operate in a bistable regime with hysteresis. The original nozzle was designed to fall on the boundary between the two regimes which was believed to be ideal for a low hysteresis, on/off valve. However, the test results showed that the valve was behaving as though it was strongly bistable vith large hysteresis. The first mo'tfication "B" was to reduce the height of the channels by simply reducing the thickness of the existing disk shaped element. As shown from the curve this change should have made the valve more proportional and less likely to have problems. It proved to be only slightly better. A second modification "C" opened the nozzle exit diameter which forced us back towards the bistable regime but reduced the ratio of control flow to supply flow (turn down ratio) which also made control easier by requiring less control air. Testing of this design was also better but still far from acceptable. The last two designs "D and $E$ " were new fluidic components with identical dimensions but with different relative locations between. the control and supply ports. These designs further improved the turndown ratio and made the valve more proportional. Figure 19 is a plot of this performance which was better, but not adequate. Based upon these test. results it was concluded that the problem was probably not component design related but was more basic. The new hypothesis which was formed was that air was probably backing up into the slurry (water) feed line during most of the cycle. The slurry (water) was not able to move far enough during the short time that the air was off to allow it to reach the vortex chamber, To test this hypothesis and to provide a $\mathrm{fix}$ for the problem, a check valve was designed into the slurry supply line to prevent the slurry from being forced backwards by the control air.

Backup injector 非 was then tested with a check valve in the CWS supply line (Figure 20). This injector had pressure transducers in both the slurry feed line and in the control air passage between the solenoid valve seat and the vortex valve. This injector also ran very well with control air pressures of 2,000 to 3,000 psi and water pressures at one half of these values. Examination of the pressure traces showed that the water pressure responded very slowly and that injection durations were twice as long as the control air signal was off. 


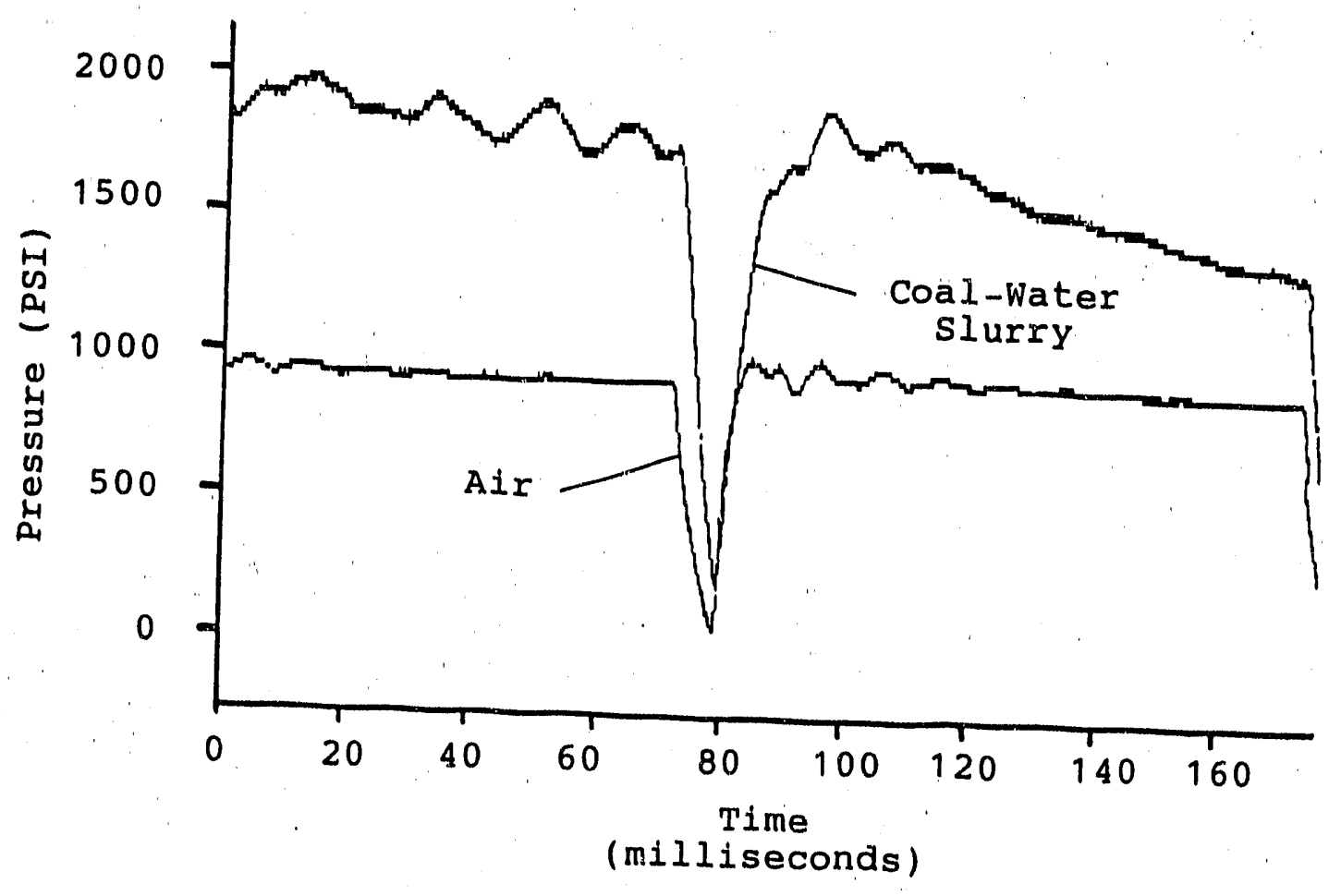

FIGURE 19. BACK-UP INJECTOR \#2 PERFORMANCE

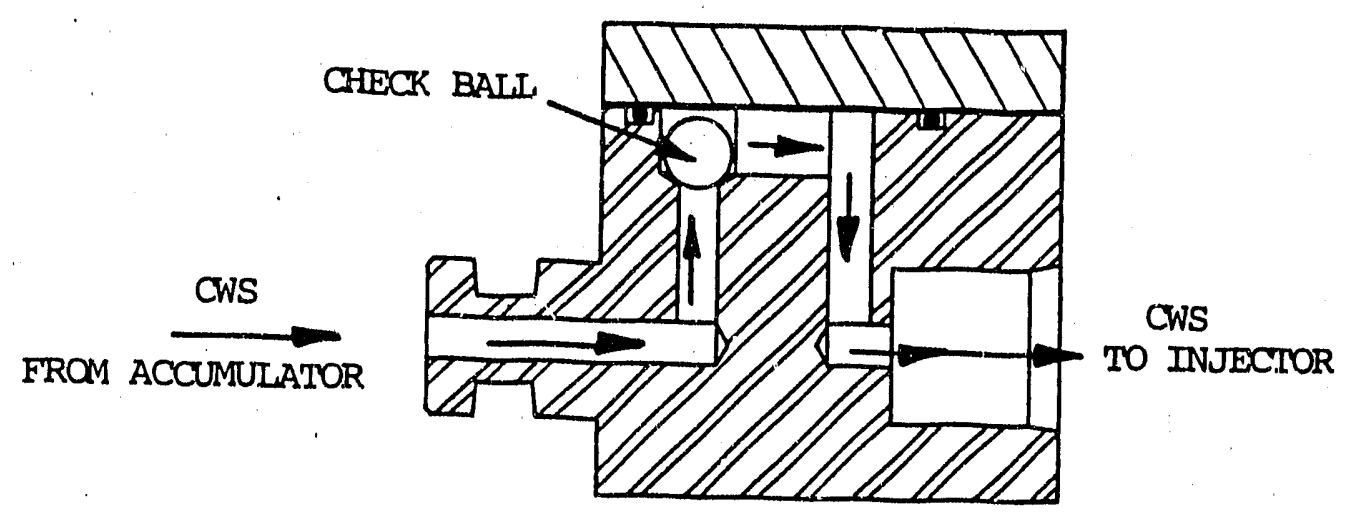

FIGURE 20. CWS FEED CHECK VALVE

Based upon this limited success we then ran the injector with coal-water slurry. Unfortunately, the injector plugged before any data could be obtained.

The Teknocraft injector (非) was tested using water instead of CWS with a check valve in the slurry supply line. The injector worked reliably at high pressures. Unfortunately, fuel injection duration was excessively long. Since this injector had the control air valve seat very close to the vortex valve, a pressure transducer was not installed in the control air line to diagnose whether the response problem was associated with the solenoid valve. Switching 
to CWS, the infector operated properly with control air pressures of only 500 psi, but attempts to raisc the pressure resulted in erratic operation. After five minutes of testing, the system was stopped to see if it would restart. upon restart it was noted that the heater (which was left on) had dried out the slurry that remained in the nozzle.

To improve the response time of the injector, a second smaller check valve was installed in the slurry line immediately adjacent to the vortex valve entrance. Tests with water showed that the injection duration was reduced to 9 ms, which was still long but adequate for low speed engine testing. Flow rates ranged from 0.05 to $0.18 \mathrm{~kg} / \mathrm{min}$, which corresponded to a medium to high power fuel range. Tests were conducted using CWS with control air pressure at 3,000 psi and CWS pressure at 1,500 psi. After two minutes of successful operation the control air pressure had dropped to 2,500 psi and the injector was stopped by turning off the electronic driver circuit. During the shutdown, CWS flowed into the control air port and seized the solenold plunger.

To lessen the likelihood of contaminating the solenoid with CWS, additional tests used a purge system which allowed the injector to be run on water both before and after testing. Using the purge system, the injector was able to stop and restart and injection durations of $5 \mathrm{~ms}$ were achieved.

\subsection{ENGINE TESTING}

Based upon the successful bench test results, the Teknocraft injector was installed in the test engine. The initial tests consisted of running the engine on the diesel fuel injector and flowing air through the control port continuously to prevent combustion products from flowing backwards into the solenoid valve. It was noted that increasing the contrul air pressure resulted in better combustion of the diesel fuel in the prechamber with the smoke level reducing from a Bosch 非 to a Bosch $\# 3$ and an increase in engine power. This result was caused by the arrangement which we used to install the pilot fuel injector, which was not optimal. To simplify installation we used a standard multi-hole stanadyne fuel injector located in the side of the precombustion chamber. This resulted in fuel spraying backwards intn the top of the prechamber which led to local areas not having adequate oxygen to burn all the fuel which is sprayed into them. Therefore by injecting air into these areas we were able to help burn more of the fuel. 
The engine was tested using Otisca Blue Gem seam CWS from barrel 非68. The engine was started and warmed up with diesel fuel with the control air pressure held at $1,000 \mathrm{psi}$. CWS was fed to the injector but the engine did not respond. After a short time the injector failed and filled the engine with CWS. Disassembly of the injector revealed combustion deposits and CWS in the solenoid assembly and the control air circuit. The injector was then modified to provide a check valve in the control air passage between the valve seat and the vortex chamber to prevent combustion products and CWS from contaminating the solenoid valve (Figure 21). The next engine test resulted in successful dual fuel (diesel pilot and CWS main injection) operation for ten minutes with
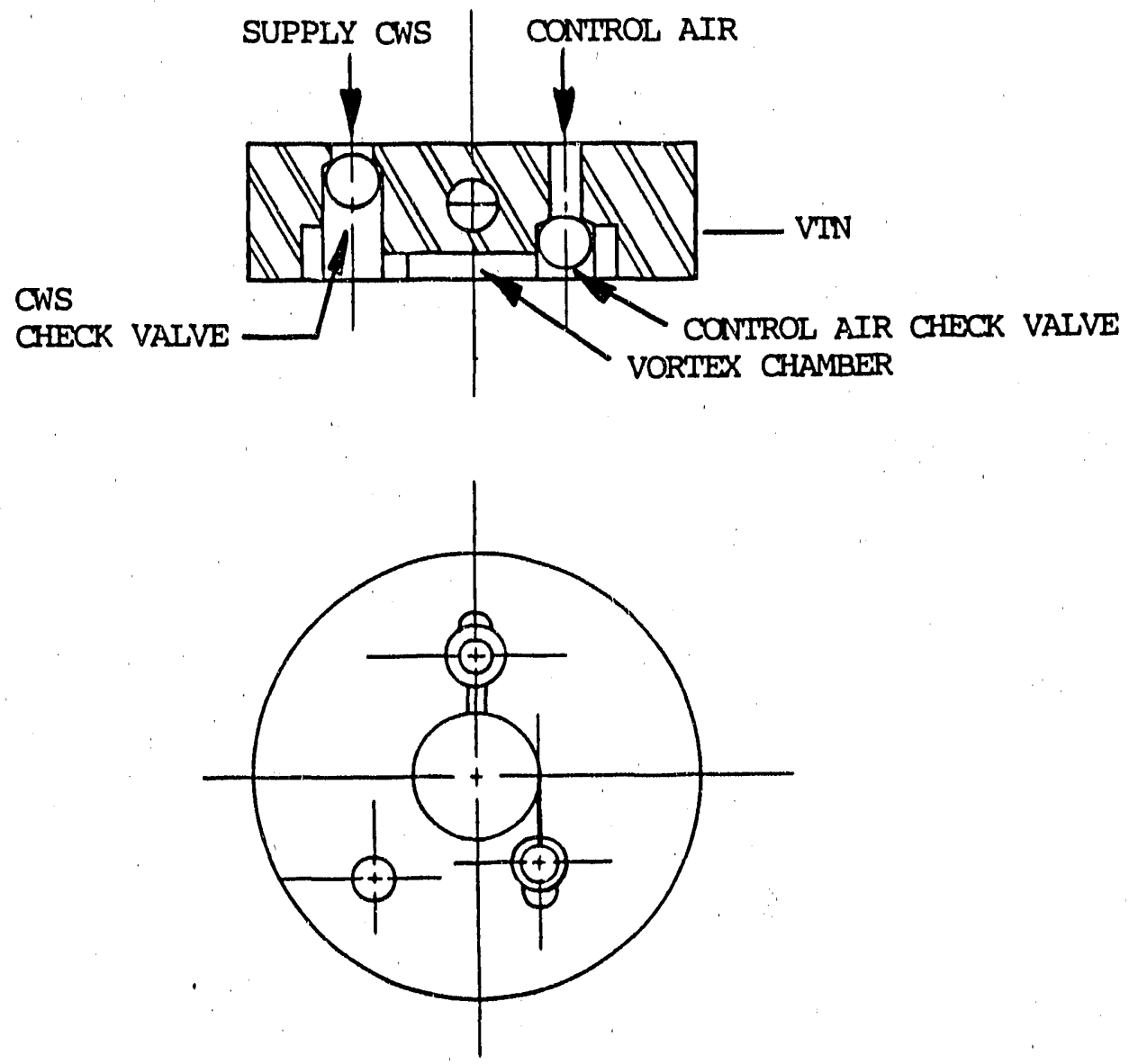

FIGURE 21. CONIROL ȦIR \& CWS CHECK VALVES IN \#3 INJECTOR 
control air pressure set to 2,000 psi and the slurry pressure set to 600 psi. After the air pressure dropped below 2,000 psi the injector was purged with water and both air and slurry systems stopped (while the engini continued to run on diesel fuel). The fluidic system was restarted after the air compressor had recharged the accumulator. The control air pressure was set at 3,000 psi and slurry pressure at $1,500 \mathrm{psi}$. When the injector was turned on the engine ran very well. The diesel fuel was turned completely off and the engine ran for 30 seconds on 100 percent CWS before the injector quit flowing. The injector was again shut down but additional attempts to restart it were not successful. Inspection of the injector revealed deposits on the solenoid plunger which were either CWS or combustion products.

The next test was run with the same hardware configuration as above but with an additional flowmeter installed in the control air line. Examination of airflow showed that airflow would increase with increased pressure up to 3000 psi at which point the alrflow would fall drastically. The engine ran for 5 minutes at 2500 psi air pressure before the air pressure dropped below allowable limits. Attempts to restart the injector were not successful. Inspection revealed combustion deposits on the solenoid plunger. The only possible source for the large drop in air flow was identified as an 0-ring which was used as a backup seal between the fluidic nozzle plate and the injector body that could possibly be squeezed and obstruct the air flow passage. Therefore, to eliminate this possibility, the o-ring was removed.

The last engine test was started on diesel fuel with the control air pressure set at $2500 \mathrm{psi}$. The engine ran continuously for 30 minutes on CWS and diesel fuel. It was noted by observing the flowmeter in the control air line that the flow did not decrease when the pressure was raised when the pressure reached $3,000 \mathrm{psi}$ as it had done in the previous test. Since the flowmeter which is normally used for diesel fuel flow was used for the control air a diesel fuel flow rate could not be obtained. 100 percent CWS operation was not achieved during this test as the precombustion chamber temperature dropped from 1,034 degrees $F$. to 850 degrees $F$. when the CWS fuel was introduced. Following a one hour shutdown of the CWS injector to recharge the air tanks, a diesel fuel leak was noticed which stopped the test program. 


\subsection{ENGINE DATA ANALYSIS}

Despite the lack of significant runing time, some data was collected during the last engine test. Figures 22 and 23 are plots of cylinder pressure, calculated rates of pressure rise and pressure versus volume diagrams for the diesel fuel and CWS/diesel fuel points respectively. The following table (Table 3) is a summary of the data at these two points and for a point taken at approximately the same conditions with the "Innovative Coal - Fueled Diesel Injector" developed and tested by Adiabatics as part of DOE Contract No. DE-AC21-88MC25132:

TABLE 3

ENGINE TEST DATA

(FLUIDIC INJECTOR) (NOVEL INJECTOR)

FUEL

DATE :

CWS FLOW (KG/MIN)

DIESEL TIMING (deg BTDC)

CWS TIMING (deg BTDC)

ENGINE SPEED (RPM)

DYNO LOAD (FT-LB)

POWER (HORSEPOWER)

PRECHAMBER TEMP (F)

INTAKE AIR TEMP (F)

EXHAUST TEMP (F)

PEAK CYLINDER PRESSURE (MPa)

PEAK RATE OF PRESS RISE (MPa/DEG) 0.25
DF2

$11-21-89$

N.A.

18

N.A.

1000

16.3

3.1

1034

213

729

4.75

4.75
$\mathrm{DF} 2+\mathrm{CWS}$

CWS

8-24-89

0.105

N.A.

18

29

1000

1000

55

55.1

10.47

10.46

$1400+$

163

987

800

5.2

6.7

0.285

Examination of the data shows that the combustion efficiency of the fluidic injector is much worse than the previously tested CWS injector in the same engine. Comparing the fluidic infector point with DF2 and CWS to the straight DF2 point (both points have the same diesel fuel flow rate) it is noted that the power contribution of the $0.121 \mathrm{KG} / \mathrm{MIN}$ of CWS amounted to $7.37 \mathrm{HP}$ (10.47 3.1) whereas the previous 100 percent CWS point generated 10.46 HP with a CWS 

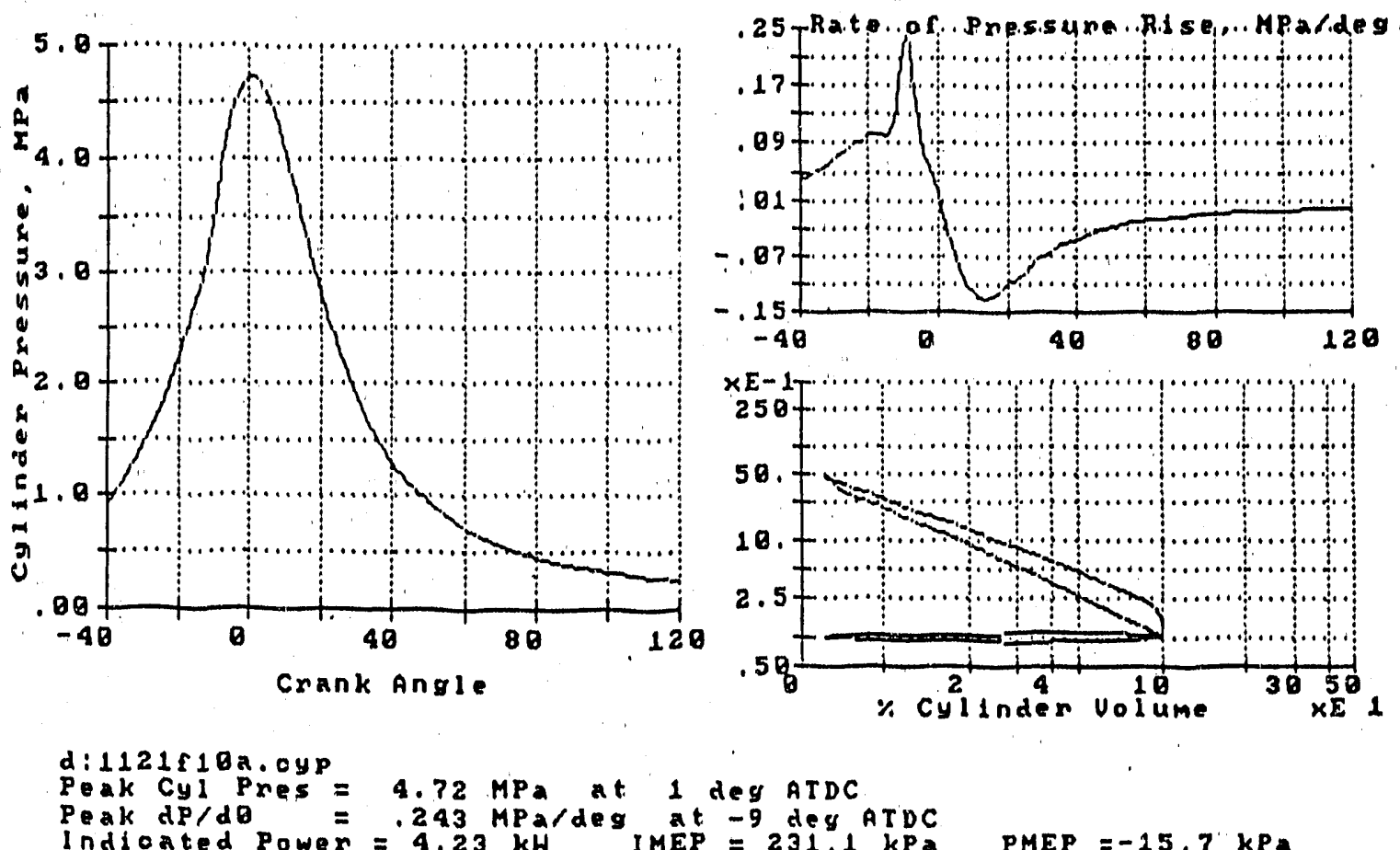

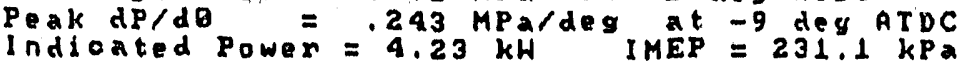

PMEP $=-15,7 \mathrm{KPa}$

FIGURE 22. DIESEL COMBUSTION
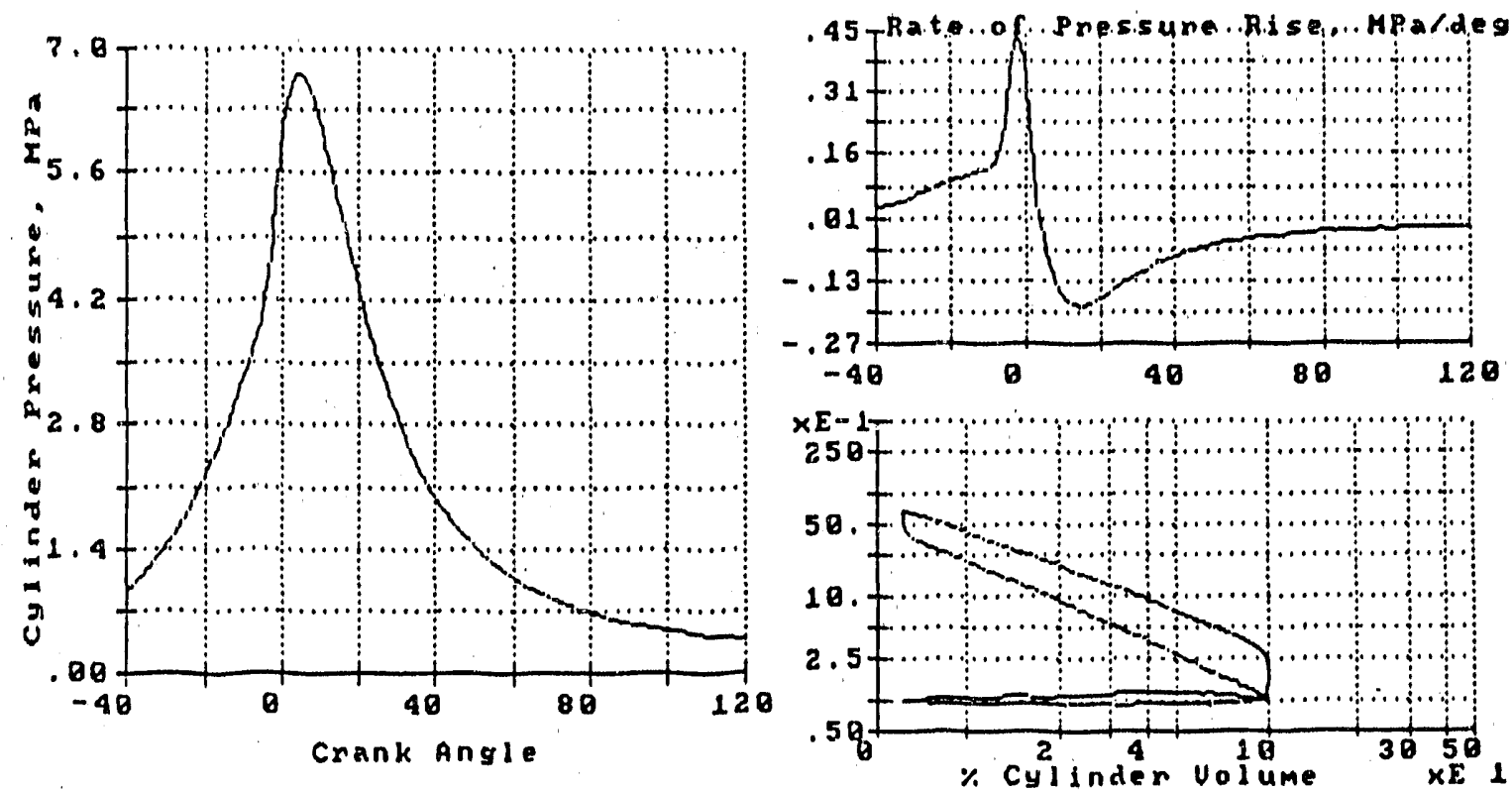

d: $1121 f 18 b .0 y p$

Peak Cyl Pres $=6.71 \mathrm{MPa}$ at 4 deg ATDC

Peak dP/dO $=.442 \mathrm{MPa} / \mathrm{deg}$ at -2 deg ATDC

Indicated Powe $=11.31 \mathrm{kH}$ IMEP $=617.7 \mathrm{kPa}$

PMEP $=-19.0 \mathrm{KPa}$

FIGURE 23. COAL WATER SLURRY/DIESEL 
flow of $0.105 \mathrm{KG} / \mathrm{MIN}$. Putting this on a percentage basis the fluidic injector has a specific fuel consumption 63 percent higher than the "innovative" injector. The reason for this poor performance is probably the reduced temperature in the precombustion chamber which slows down the combustion process.

\subsection{SUMMARY AND CONCLUSIONS}

This report describes the design, bench testing and engine testing of a fluidic fuel injector using compressed air as a control fluid. The program can be considered sor shat of a success as many problems were overcome and a fluidic injector was able to operate a single cylinder diesel engine. However, it is concluded that the selected approach was not practical and should not be further developed. The reason the injector was not practical is because of its parasitic power requirement. Figure 24 is a plot of the power required to compress the air for the fluidic injectors concrol air stream. For a three stage compressor with 80 percent efficiency per stage and three stages of intercooling at 80 percent effectivity, it would be necessary to use 20 percent of the engine"s output power just to compress the control air.

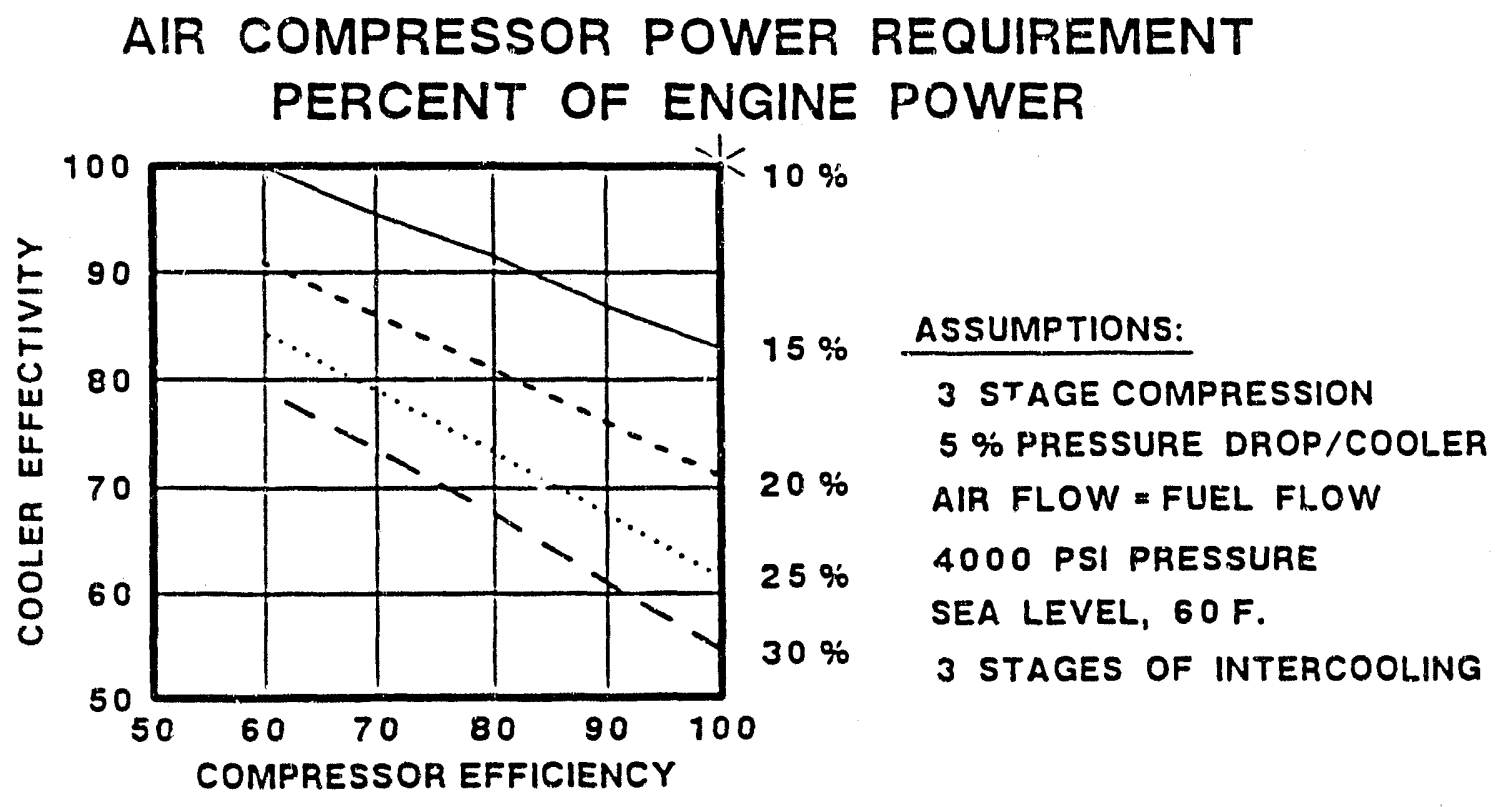

FIGURE 24. AIR COMPRESSOR POWER REQUIREMENT PERCENT OF ENGINE POWER 
In earlier tasks, several different fluidic approaches were evaluated and bench tests on several components were conducted. As a result of this testing, the VTN was the only "purely" fluidic approach which showed promise. Other approaches were ruled out primarily because of the unique characteristics of CWS (that it cannot be repeatedly pumped to high pressures without major change of properties).

In selecting the VTN approach we had the option of using either air, water, or steam as a control fluid. Air was selected because a workable system which required injection of a mass of water equal to the mass of CWS being injected into the prechamber was believed to be impractical. It was felt that this much water would excessively cool the prechamber and inhibit ignition. Steam was ruled out because of the complexities of requiring a 3000 psi steam system.

As it turned out, a "purely" fluidic injector work could not be made to work. The addition of the check valves in the CWS feed line and control air line turned out to be essential to make the injector work. While it is probably possible to make these devices reliable, some of the attractiveness of a purely fluidic injector was lost.

The major development which most impressed the researchers on this program has been the atomization characteristics of the vortex swirl nozzle. This design dramatically reduces the pressure required to atomize CWS as compared with a hole type nozzle.

\subsection{RECOMMENDATIONS FOR FUTURE WORK}

Based upon the results and findings of this program, the following recommendations are suggested for future work:

- Incorporate the vortex swirl nozzle into a conventional diesel type injection nozzle to replace the spray holes. This type of nozzle is probably only applicable to a prechamber type engine or a direct injected engine with a relatively narrow and deep combustion bowl in the piston. Figure 25 is a drawing showing a conventional hole type diesel nozzle on the left and the same injector with a vortex swirl nozzle on the right. The advantages of the vortex nozzle will be 
reduced wear resulting from improved atomization at lower injection pressures.
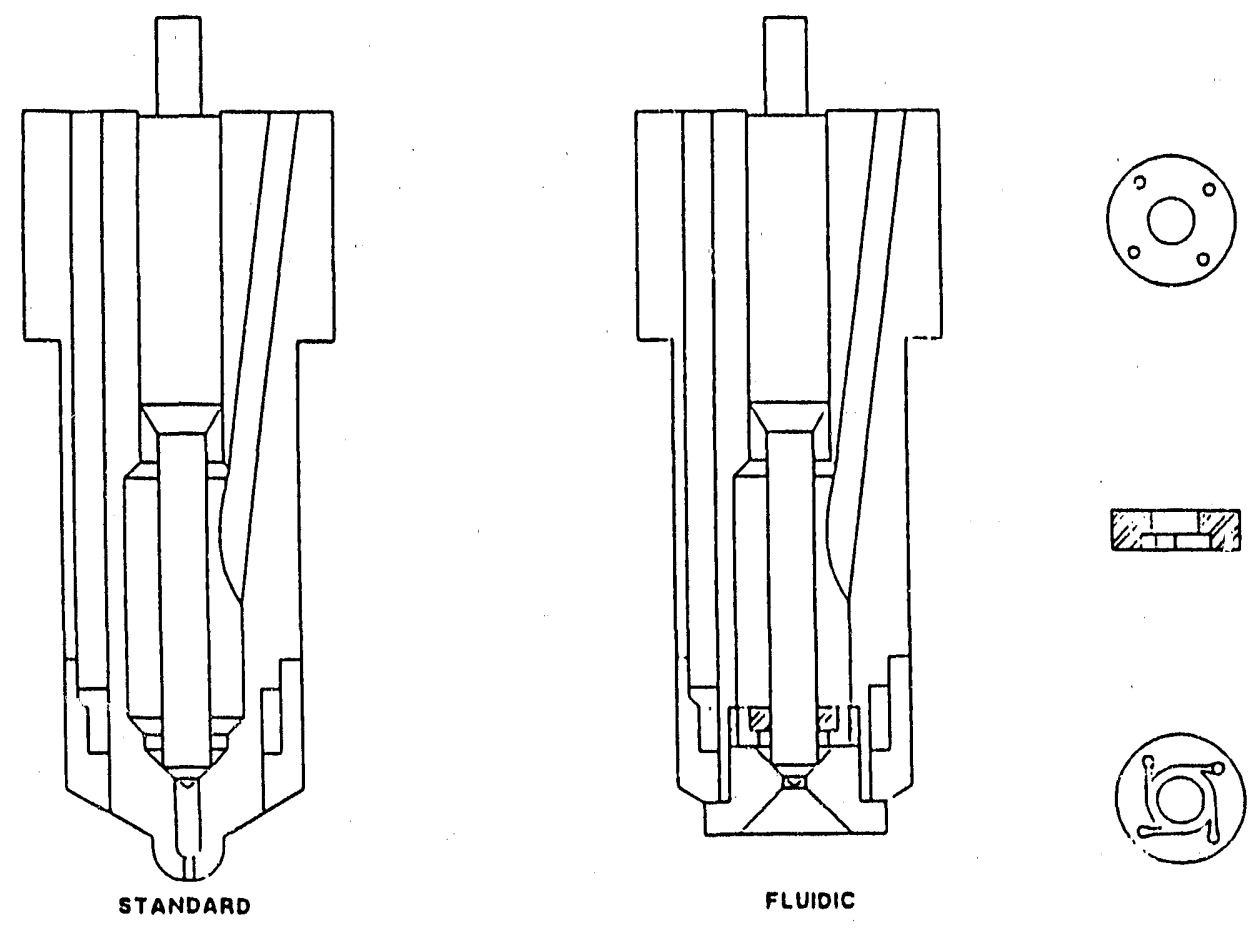

FIGURE 25. HYBRID INJECTOR

- Explore the potential of using the current fluidic injector with high pressure steam as the control fluid. High pressure steam (3,000 psi, 750 degrees F.) can be economically generated by pressurizing feed water to 3,000 psi and using exhaust heat (with an auxiliary coal fuel fired heater for startup) in a single pass boiler to flash the water into steam. Using this approach, the parasitic power requirements are less then one percent of engine power and are therefore no longer a problem. The use of high temperature steam at 750 degrees $F$, compared with the room temperature air which was used for the testing, also aids in keeping the injector warm and in preventing the prechamber from becoming excessively cool. 


\subsection{REFERENCES}

1. Badgley, P.R., "Management Plan for Fluidic FUel Feed System", submitted to DOE METC, December 17, 1986.

2. Badgley, P.R., and Holmes, A.B. "Task I Topical Report and Test Plan for Fluidic Fuel Feed System", submitted to DOE METC, December 11 , 1987.

3. Badgley, P.R., Holmes, A.B., and Kumar, S., "Task II Topical Report for Fluidic FUel Feed System", submitted to DOE METC, February 15, 1990.

4. Som, S.K., and Mukherjee, "Theoretical and Experimental Investigations on the Formation of Air Core in a Swirl Spray Atomizing Nozzle," Applied Scientific Research 36: (1980) pp.173-196, Martinus Nijhoff Publishers bv, The Hague, (Printed in the Netherlands).

5. Wormley, D.N., "An Analytical and Experimental Investigation of Vortex Type Fluid Modulators," PhD thesis, Department of Mechanical Engineering. Massachusetts Institute of Technology, Cambridge, Mass, Oct. 1967.

6. Holmes, A.B. "Fluidic Fuel Feed System," Proceedings of the Annual Heat Engines and Gas Stream Cleanup Systems Contractors Review Meeting, DOE/METC (DE87001072), April, 1987. 


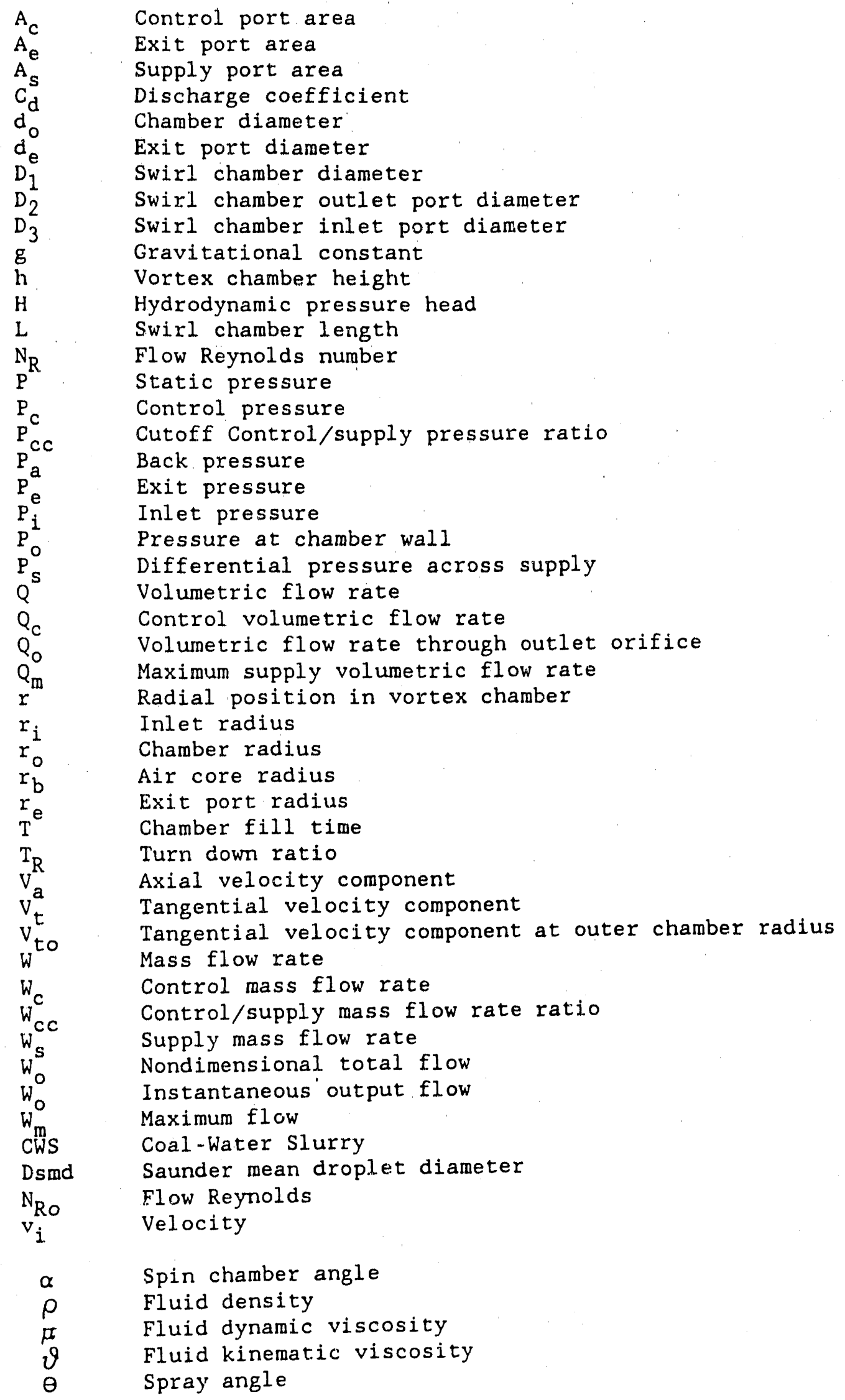



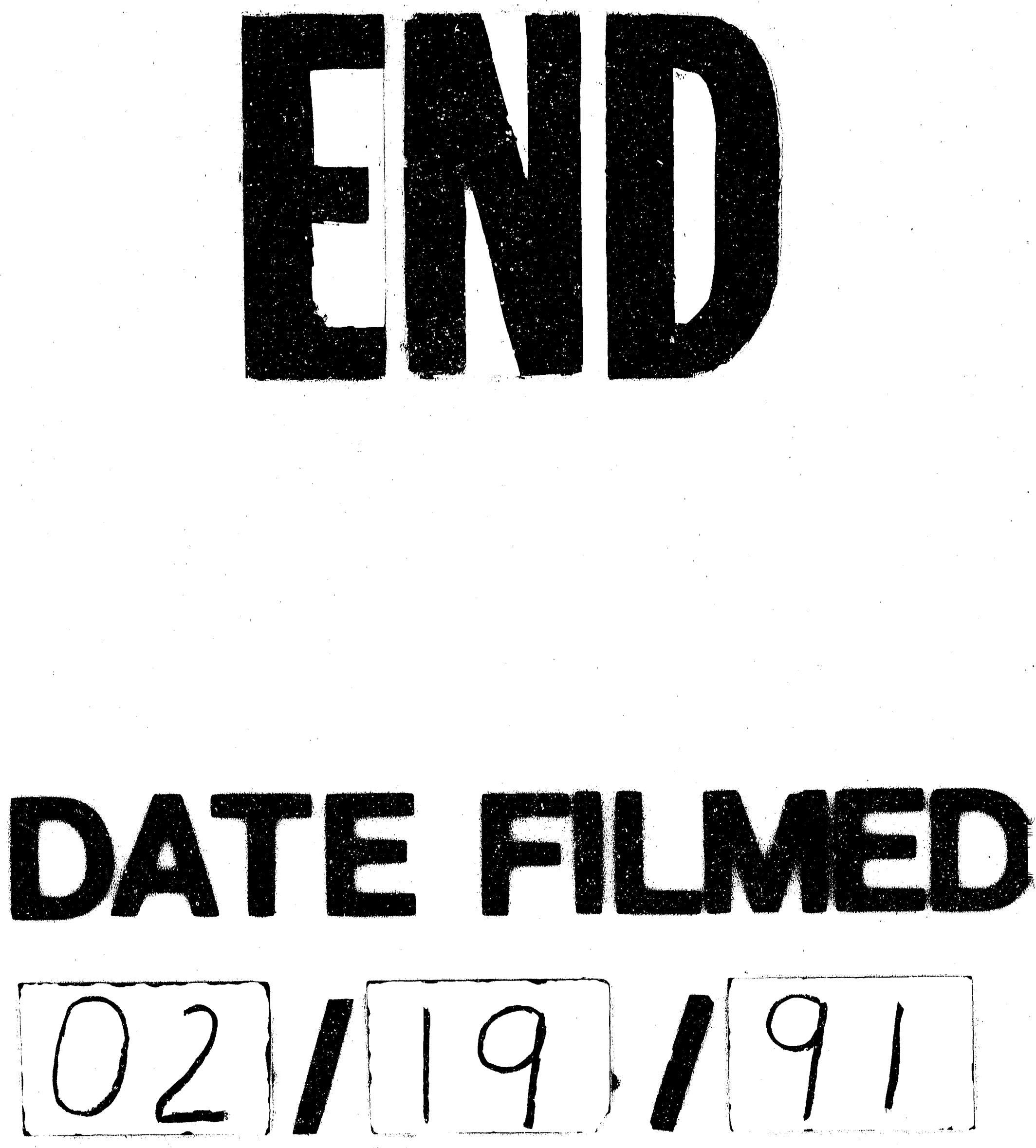
